\title{
A MICRO-INSTITUTIONAL INQUIRY INTO RESISTANCE TO ENVIRONMENTAL PRESSURES
}

\author{
OLIVER SCHILKE \\ The University of Arizona
}

\begin{abstract}
This article contributes to the emerging stream of micro-institutional research, which zooms in on the internal organizational processes that are responsible for organizations' differential responses to the external environment. Specifically, the investigation offers new knowledge of how organizational identity processes can shape whether decisionmakers will resist versus give in to environmental pressures. Building on the notion that organizational identity acts as a filter through which decision-makers relate to the external environment, I develop the theoretical argument that strong organizational identification increases resistance to environmental pressures due to two mechanisms: (1) it bolsters the decision-maker's certainty and (2) it deflects the decision-maker's attention from the environment. A series of laboratory experiments not only test the mediated relationship between organizational identification and resistance to environmental pressures but also contrast different types of organizational identity. The empirical results support the hypothesized positive link between organizational identification and resistance, which becomes particularly strong when the organizational identity is normative (vs. utilitarian). The findings reported here enrich institutional theory by adding microfoundations to organizational practice adoption decisions and shedding new light on relevant enabling conditions for agency and within-field heterogeneity.
\end{abstract}

Institutional theory is currently undergoing a fundamental shift from a formerly purely macro-level approach toward a comprehensive multilevel paradigm that explicitly incorporates individuals (Bechky, 2011; Fine \& Hallett, 2014; Thornton, Ocasio, \& Lounsbury, 2012). This transformation is driven by the recognition that "much analytical purchase can be gained by developing a micro-level component of institutional analysis" (Powell \&

The author is thankful for the insightful comments provided by associate editor Pursey Heugens and by three anonymous reviewers. The author also gratefully acknowledges the helpful comments on earlier versions of this paper provided by Jeannette Colyvas, Karen Cook, Joseph Galaskiewicz, Jeffrey Lucas, Carrie Oelberger, Nathan Podsakoff, Davide Ravasi, Pat Reilly, Martin Reimann, Gabriel Rossman, Leigh Plunkett Tost, Edward Walker, and, last but most certainly not least, Lynne Zucker. The paper also benefitted from discussions with participants of the University of Arizona Sociology Brownbag, the University of Arizona Macro Reading Group, the Stanford University OB Macro Lunch, the UCLA Knowledge and Cognitive Systems Working Group, the Harvard Business School Speaker Series in Organizational Behavior, the Alberta School of Business McCalla Seminar Series, the Tuck School of Business Strategy and Management Seminar Series, the
Colyvas, 2008: 276) to complement earlier macro-level accounts, with the goal of making the theory both more precise and more general as a result (Thornton \& Ocasio, 2008). After decades of neglect, the motivations, cognitions, backgrounds, and behaviors of individual actors have thus moved to the foreground of institutional inquiry (Boxenbaum, 2014; Lawrence, Suddaby, \& Leca, 2011; Zilber, 2016).

American Sociological Association 2015 Annual Meeting, the 2015 Academy of Management Meeting, and the 2016 Group Processes Conference. An earlier version of this paper was a finalist for the 2015 Pondy Best Dissertation Paper Award, and an extended abstract was included in the 2015 Academy of Management Annual Meeting Proceedings (OMT Division). The author is thankful for able research assistance by Jonathan Blair Evans, Mariam Hambarchyan, Jessi Mariah Rivin, and Katelyn Wirtz.

Funding: The author conducted this research in part while supported by a UCLA Dissertation Year Fellowship. This material is based upon work supported by the National Science Foundation under Grant Number 1302306. Any opinions, findings, and conclusions or recommendations expressed in this material are those of the author and do not necessarily reflect the views of the National Science Foundation. 
However, several important questions related to the role of individuals in institutional theory have remained largely unaddressed so far. The current investigation tackles one such theoretical puzzle that is particularly pressing: Facing the same environmental pressures to adopt certain organizational practices, why is it that some organizational decision-makers resist those pressures while others give in to them and conform to isomorphic templates? Answering this question is of critical importance for at least two interrelated reasons, the first pertaining to its distinctive focus on individual decisionmakers as the unit of analysis and the second to its explanandum of resistance to adopting organizational practices.

First, in contrast to the conventional macroinstitutional emphasis on field-level homogeneity, an analytical focus on decision-makers has significant potential for explaining within-field heterogeneity-that is, why not all organizations in a field are the same (Tolbert, David, \& Sine, 2011; Zucker, 1991). While there is no doubt that environmental pressures can be very powerful, they are rarely so strong that all organizational decisionmakers have no choice but to succumb to them unreflectedly (Binder, 2007; Fiol \& O’Connor, 2003). Indeed, an increasing consensus is emerging that decision-makers can exercise considerable discretion in deciding to what extent their organization becomes isomorphic with the environment. Therefore, a revised account that does away with the longstanding "institutional dope" assumption (DiMaggio \& Powell, 1991), and that instead endows decisionmakers with the ability to subjectively make sense of the environment, has great potential to significantly broaden our understanding of the adoption of institutionalized prescriptions. Unfortunately, relevant micro-sociological processes, which "form a necessary link in the causal chain connecting abstract isomorphic pressures to concrete organizational actions, are all too often merely assumed or even ignored by institutional theorists" (Heugens \& Lander, 2009: 76). Consequently, greater attention to the local conditions and how they shape the way decision-makers perceive, interpret, and act on the environment are indispensable for institutional inquiry to move forward (Bechky, 2011; Creed, Hudson, Okhuysen, \& Smith-Crowe, 2014; Hallett, 2010b; Powell \& Bromley, 2015). It is this call to develop the microfoundations of institutions and to bring "individuals back into institutional theory" (Lawrence et al., 2011: 53) that provides a key motivation for the current investigation.
Second, a reinvigorated commitment to explaining variations in resistance to adopting organizational practices (e.g., Dhalla \& Oliver, 2013; Pache \& Santos, 2010) is warranted for both practical and theoretical reasons. From a practical perspective, whether isomorphic templates for organizing are adopted by an organization can have major implications not only for that organization's social evaluation but also for its technical efficacy and differentiation from competition, with deviating organizations often outperforming conformers in terms of profitability (Barreto \& Baden-Fuller, 2006; Meyer \& Rowan, 1977; Zucker, 1987). This investigation uncovers an important micro-level predictor of such deviance and thus perhaps of an organization's competitive advantage. From a theoretical perspective, knowledge about the conditions under which actors resist environmental practices directly speaks to the enduring agency debate (e.g., Heugens \& Lander, 2009; Zilber, 2002) - that is, the question of whether people are mere institutional carriers who passively reproduce their external world versus active human agents who purposefully interpret and resist their environment. Developing a middle-ground perspective that transcends the conventional dichotomy of structure versus voluntarism and unpacks the conditions under which people will fall closer to one or other end of this continuum is an important element in building a richer notion of agency and contingent actorhood in institutional theorizing (Battilana, 2006; Battilana \& D'Aunno, 2009), which has the potential to take institutionalism beyond a restricted model of constraint.

Despite the great relevance of understanding how decision-makers experience and react to environmental pressures to adopt institutionalized prescriptions, prior investigations into this issue are severely limited (cf. Suddaby, 2010; Zilber, 2008). We know very little about whether and how the characteristics of decision-makers and their immediate context shape organizational resistance. Traditionally, scholars studying responses to adoption pressures have used a macro lens (see Scott, 2014, for an overview), whereas recent micro-level investigations evoking the notions of institutional entrepreneurship (Battilana, Leca, \& Boxenbaum, 2009), institutional work (Lawrence et al., 2011), or inhabited institutions (Hallett \& Ventresca, 2006) have so far largely bracketed organizational templateadoption decisions. As Chandler and Hwang (2015) emphasized, the institutional practice adoption and microfoundations literatures have yet to be integrated 
systematically in order to fully grasp the reasons for organizational heterogeneity.

My particular approach to redressing this oversight and identifying an important source of decision-makers' heterogeneous responses to institutional pressures is motivated by the need to avoid both the over-socialized view of earlier neoinstitutional theorizing as well as the reductionist trap of overly utilitarian, atomistic accounts (Powell \& Colyvas, 2008). In most cases, organizational decision-makers do not respond to institutional pressures in isolation but in the context of their particular social setting (Hallett, 2010a). Thus, in order to capture human beings in their collective character, it is important to explicitly account for the effect of their immediate social context on cognition and behavior (Battilana \& D'Aunno, 2009; Fine \& Hallett, 2014).

In terms of decision-making related to practice adoption, an especially salient immediate social context is undoubtedly that of the organization (Suddaby, Elsbach, Greenwood, Meyer, \& Zilber, 2010; Zilber, 2002). Therefore, I build on recent efforts to infuse institutional theory with organizational identity processes (Dejordy \& Creed, 2016; Greenwood, Raynard, Kodeih, Micelotta, \& Lounsbury, 2011; Hatch \& Zilber, 2012; Kraatz \& Block, 2008; Thornton et al., 2012) to argue that actors' sensemaking and adoption decisions are substantially influenced by their identification with and identity of the organization. The concept of organizational identity roots the individual in the organizational context (Ashforth, Rogers, \& Corley, 2011), structures ongoing organizational sensemaking activity (Fine \& Hallett, 2014), and provides an ideal window for institutionalists to examine micro-level dynamics in organizational decision-making because it reflects the taken-for-granted collective character of organizational members and avoids the imagery of muscular, heroic individuals (Scott, 2014). Organizational identity forms a critical link between the institutional environment and the cognition and behavior of organizational decision-makers (Glynn, 2008; Thornton \& Ocasio, 2008), but it has yet to be systematically examined in conjunction with organizational responses to environmental pressures.

Building on the notion that organizational identity represents an important filter through which the environment is perceived, interpreted, and acted upon (e.g., Greenwood et al., 2011; Raffaelli \& Glynn, 2014), this article develops a novel theoretical argument regarding the role of organizational identity processes in decision-makers' responses to environmental pressures. I argue, and empirically demonstrate, that strong organizational identification increases organizational decision-makers' resistance to environmental pressures, and that this effect is due to two cognitive mechanisms related to how they perceive themselves and the environment. Specifically, strong organizational identification is shown to (a) bolster the decision-maker's certainty and (b) deflect the decision-maker's attention from the environment. Moreover, this research moves beyond studying identification to compare the consequences of different types of organizational identity, specifically contrasting a normative and a utilitarian ideal type. Overall, the article addresses the following three research questions: (1) Does organizational identification affect decision-makers' resistance to environmental pressures?; (2) If so, why?; and (3) What particular attributes of an organization's identity modulate this resistance?

This investigation makes several important contributions. First, it adds to recent micro-institutional inquiry by shedding new light on the role of decision-makers' cognition in organizational practice adoption. While in no way devaluing the impact of the external environment on organizations, microinstitutionalists have called for greater emphasis on interpreting macro-level environments through the lens of micro-level perceptions (e.g., Bitektine \& Haack, 2015; Greenwood et al., 2011; Powell \& Colyvas, 2008; Suddaby, 2010; Thornton et al., 2012), and they have identified the need for more theorizing dedicated to the individual-level processes through which environments affect organizations. Because organizational decision-makers mediate the interface between organizational environment and organizational action, we can fully grasp the nature and effect of external institutions only by understanding the cognitive processes involved in dealing with those institutions (Barley, 2008; George, Chattopadhyay, Sitkin, \& Barden, 2006; Glaser, Kroezen, \& Thornton, 2015). In particular, identifying the local contexts and cognitive processes that shield decision-makers from external institutions is critical for understanding relevant enabling conditions of actorhood, an issue that researchers have identified as particularly critical to advancing the agency debate in institutional theory (Battilana, 2006; Powell \& Bromley, 2015). Specifying such enabling conditions will "help ease the unfortunate dichotomy between heroic actors and 'cultural or institutional dopes'” (Hwang \& Colyvas, 2011: 63). Contributing to this line of inquiry, the 
current investigation highlights organizational identity as a central local condition promoting decision-makers' resistance to environmental pressures. It provides support for the notion that an individual's agency is strongly guided by his or her social identification and identity. Further, it specifies two concrete cognitive mechanisms-certainty and attention-that explain actors' variation in resistance, thus directly addressing repeated calls for greater insight into the cognitive processes through which people experience and make sense of institutional pressures (Battilana \& D'Aunno, 2009; Bechky, 2011; Thornton \& Ocasio, 2008; Zilber, 2002).

In addition to these theoretical advancements, this article makes a methodological contribution by developing a novel experimental setup with manifold potential uses for future institutional inquiry. For a long time, experiments have been virtually unheard of in institutional research, but recently scholars have begun to follow up on Zucker's (1977) seminal work and leverage the ability of experimental methods to isolate theoretical factors of interest and clarify the mechanisms underlying causal effects. Bringing quantitative micro work to institutional theory, experiments represent a neglected but much-needed tool for uncovering micro-level processes and explaining how individuals experience, make sense of, and react to institutions. Experiments thus allow for building new causal theory by addressing key questions at the heart of institutional theory that would be difficult to study with other methods (Bitektine, Lucas, \& Schilke, 2018; Haack, McKinley, Schilke, \& Zucker, 2016). The procedures and findings reported in the current research should encourage future scholars to employ experimental methods when studying institutional phenomena, thus helping to expand the "resource space" of potential contributions available to the institutional research community (Bitektine, 2009; Bitektine \& Miller, 2015).

\section{THEORETICAL BACKGROUND}

\section{Toward a Micro-level Component of Institutional Theory}

Why do organizations adopt practices whose material benefits are difficult to assess even in retrospect? This important question is at the core of institutional theory. A long line of institutional research suggests that various mimetic, normative, and coercive pressures cause organizations to adopt templates that make them isomorphic with their environment (Scott, 2014). Following the foundational works of Meyer and Rowan (1977), Zucker (1977), and DiMaggio and Powell (1983), institutionalism has developed into a leading-perhaps the dominant-perspective in organizational analysis these days (Greenwood, Hinings, \& Whetten, 2014; Powell \& Bromley, 2015).

Despite its significant contributions, institutional theory has become the subject of increasing criticism for its overly strong emphasis on macro-level issues (Bitektine, 2011; Hallett, 2010b; Powell \& Colyvas, 2008). Traditionally, the theory focused heavily on environmental drivers of organizational behavior while neglecting the processes by which organizational actors cope with the environment and which may thus explain why organizations differ in their acceptance of versus resistance to external pressures (cf. Felin, Foss, \& Ployhart, 2015; George et al., 2006). That is, by viewing the source of organizational behavior as exogenous, institutionalists have largely "black boxed" the organization (Gavetti, Levinthal, \& Ocasio, 2007; King, Felin, \& Whetten, 2010; Zilber, 2016; Zucker, 1983).

This line of criticism is fueled by the observation that, even in the long run, many organizations will not conform to institutional pressures (Kraatz \& Zajac, 1996; Pedersen \& Dobbin, 2006). Heugens and Lander's (2009) comprehensive meta-analysis of 144 institutional studies analyzing the effect of environmental pressures on isomorphism found that, although this effect is significant, reported effect sizes are relatively small, and using environmental institutions to explain a few percentage points of the variance does not an iron cage make.

In response to such criticism, institutionalists have increasingly come to accept the notion that organizations do not simply react to environmental demands, and this opens up the way for investigations into factors that help to explain why resistance rather than conformity may characterize an organization's response (Oliver, 1991; Park, Sine, \& Tolbert, 2011). In particular, institutionalists have recently become interested in investigating factors relevant to the micro level, which can provide considerable additional leverage for understanding the reasons for variability in organizations' responses to comparable institutional environments (DiMaggio \& Markus, 2010; Zucker, 1991). Although organizations within a given institutional field are typically exposed to similar environmental pressures, these organizations' decision-makers may not experience, and consequently may not respond to, such pressures in the same way (Raffaelli \& Glynn, 2014; 
Suddaby, Viale, \& Gendron, 2016; Tolbert et al., 2011). A sharper focus on cognitive processes, which for too long have been "obscured by the macro-gaze common in contemporary neo-institutionalism" (Hallett, 2010b: 53), thus seems indispensable to explain the feasibility of varying organizational responses within the same macro-institutional environment.

In particular, the research stream on inhabited institutionalism (Hallett \& Ventresca, 2006) has recently made significant progress in illuminating the role of cognitive processes in how people engage with external institutions. Binder (2007) and Hallett (2010b), for example, demonstrated that institutions are "inhabited" by individuals who actively make sense of institutional rules through the lens of their unique experiences and local context. Similarly, Fine and Hallett (2014) argued that actors' cognitive processes play a key role in interpreting external institutions and ultimately guiding organizational action. In short, a micro-level understanding of institutional processes goes hand in hand with a cognitive lens.

Indeed, a cognitive micro-level approach to institutional theory is highly consistent with some of the theory's intellectual roots (see also Barley, 2008; DiMaggio \& Powell, 1991; Hallett, 2010b; Powell \& Colyvas, 2008; Zucker \& Darby, 2005)—especially Selznick (1957) and Berger and Luckmann (1966). In his seminal study of how institutions work, Selznick (1957: 4) insisted that "no social process can be understood save as it is located in the behavior of individuals, and especially in their perceptions of themselves and each other." Similarly, shared objectified schemas of "how things are done" are key to Berger and Luckmann's (1966) view of how individuals make sense of everyday social reality, accentuating the subjective interpretations of individuals that manifest in social groups. Notably, they highlighted that "identity is, of course, a key element of subjective reality" (Berger \& Luckmann, 1966: 194). Although social identities can stem from a variety of contexts, institutional scholars have devoted special attention to organizational identity.

\section{Organizational Identity and Institutional Theory}

Organizational identity has a long history in institutional inquiry. ${ }^{1}$ Sixty years ago, Selznick (1957: 40)

\footnotetext{
${ }^{1}$ Indeed, institutional and identity theories share various common themes and assumptions (Kroezen \& Heugens, 2012: Table 1).
}

emphasized that an "infusion [of values] produces a distinct identity for the organization." Nonetheless, it has only been relatively recently that institutionalists have rediscovered the importance of organizational identity and have started to increasingly incorporate the concept into their theorizing (Glynn, 2008; Pedersen \& Dobbin, 2006). This renewed interest in organizational identity can be at least partially explained by heightened efforts to better explain agency in the institutional theory framework. To that end, scholars have started to study the conditions under which organizations are more likely to possess agency (Battilana, 2006; Heugens \& Lander, 2009) and, in doing so, have singled out organizational identity as a potentially critical source of such actorhood (Dejordy \& Creed, 2016; Greenwood et al., 2011; Kraatz \& Block, 2008). Because organizational identity shapes decisionmakers' views about what constitutes appropriate behavior, it forms a fundamental basis for intentionality (King et al., 2010). ${ }^{2}$ As such, organizational identity is central to the very constitution of organizations as social actors who are enabled to interpret and perform their own role within the macro-institutional order. Organizational identity is thus often viewed as a much-needed corrective to the oversocialized view of traditional neoinstitutionalism (Scott, 2014).

In my research model, I build on these ideas to advance a view of organizational identity as integral to addressing this article's puzzle of why decisionmakers vary in their resistance to environmental pressures. I focus on organizational identity because (a) it roots the individual in the organizational context (Ashforth et al., 2011; Fine \& Hallett, 2014), and thus provides the linkage that is required for delving into the cognitive processes that are involved when individuals make adoption decisions on behalf of their organizations; (b) organizational identity is a key source of actorhood (King et al., 2010), and is accordingly likely to be a relevant predictor of heterogeneity and resistance; and (c) organizational

\footnotetext{
${ }^{2}$ It is worth noting that an approach to organizational identity that emphasizes the perceptions of individuals within organizations differs considerably from how population ecologists have predominantly conceptualized organizational identity in terms of market categories (cf. Gioia, Price, Hamilton, \& Thomas, 2010). Whether and how these two conceptualizations of identity interact is beyond the scope of this article (but see Gioia, Patvardhan, Hamilton, \& Corley, 2013, for a relevant discussion), and the focus here is on the former, internal perspective.
} 
identity has the quality of an objective reality for organizational members (Dejordy \& Creed, 2016) and is therefore highly consistent with the taken-forgrantedness aspect of institutional theorizing (Glynn, 2008; Pedersen \& Dobbin, 2006). Rather than conceiving of identity as a conceptually autonomous concept external to institutional theory, I consider it a central element of microinstitutionalism, in line with several other recent investigations (Dejordy \& Creed, 2016; Greenwood et al., 2011; Hatch \& Zilber, 2012; Kraatz \& Block, 2008; Thornton et al., 2012). I elaborate this view by showing how organizational identity enables decision-makers to resist environmental pressures.

\section{Conceptualizing Organizational Identity}

Two key subdimensions of organizational identity that need to be distinguished for analytic purposes are "organizational identification" and "organizational identity content" (e.g., Haslam, Postmes, \& Ellemers, 2003; Sluss \& Ashforth, 2007). Whereas organizational identification denotes the extent to which members perceive themselves as subordinate parts of the organization, organizational identity refers to the particular characteristics that are (either objectively or subjectively) shared among those members (Gioia \& Thomas, 1996; Whetten, 2006). The emphasis of organizational identification is thus on the act of classifying oneself as an organizational member (Ashforth \& Mael, 1989; Thornton \& Ocasio, 2008). It reflects an individual's perception that he or she belongs to a larger aggregate of humans delineated by an organizational boundary. Organizational identification can be thought of as a continuous concept ranging from low to high.

Organizational identity content, on the other hand, pertains to the central, enduring, and distinct attributes of the organization (Albert \& Whetten, 1985). These organizational attributes offer shared ${ }^{3}$ social meanings that individuals attribute to themselves in their roles as organizational members (Scott, 2014). Organizational identity content is a categorical concept that can be usefully represented by relevant

\footnotetext{
${ }^{3}$ The degree to which social meanings are shared by members can of course vary from organization to organization. This idea is captured by the notion of "organizational identity strength"- the extent to which identity beliefs are widely shared and densely articulated among organizational members (Ashforth, Harrison, \& Corley, 2008; Besharov \& Brickson, 2016)-which is beyond the scope of the current investigation.
}

ideal types (Thornton \& Ocasio, 2008), such as a normative and a utilitarian organizational identity (Albert \& Whetten, 1985; Gioia \& Thomas, 1996).

\section{HYPOTHESES}

Based on these considerations, I develop a research model that links organizational identity processes to resistance to environmental pressures. ${ }^{4}$ Given their distinct and complementary character (Ellemers, Spears, \& Doosje, 2002; Haslam et al., 2003), I consider the roles of both organizational identification and organizational identity content and develop distinct hypotheses for these two identity subdimensions. Moving beyond main effects, I derive relevant cognitive mechanisms that help to explain the proposed identity-resistance relationship. While cognitive underpinnings of institutions can be manifold (George et al., 2006), I focus on two processes that are particularly pertinent for my model because they simultaneously operate as key consequences of organizational identity and as relevant sources of variation in resistance (as developed below)—namely, "certainty" and "attention." Finally, I contrast different types of identity and their respective effects on resistance. In constructing my conceptual argument, I draw from extant microinstitutional theorizing where possible, but I also follow Boxenbaum's (2014) recommendation to complement and deepen these relatively nascent ideas by borrowing from relevant social psychological research, particularly as it speaks to the consequences of identity processes.

\section{The Effect of Organizational Identification on Resistance to Environmental Pressures}

The concept of identification is based on the notion that people have a tendency to classify themselves and others into social categories, including organizations (as well as religious denominations, gender, age groups, etc.) (Thornton et al., 2012). Organizational identification thus pertains to selfcategorization as a member of an organization (Thornton \& Ocasio, 2008). Importantly, strongly

\footnotetext{
${ }^{4}$ On a theoretical level, environmental pressures can be conceptualized as being of a mimetic, normative, or coercive nature (DiMaggio \& Powell, 1983), although my empirical tests later will focus on the first two types of pressures and any generalizations to coercive pressures necessarily have to remain speculative at this point.
} 
identifying decision-makers not only locate themselves in the social category of the organization but also interact with their institutional environment in terms of this category, allowing themselves to be guided by their role as a representative of the organization (Scott, 2014). As a consequence, organizational identification has profound implications for organizational decision-making as it pertains to environmental pressures.

In a way, identification transforms organizations into "institutions in their own right," immunizing them against external pressures for compliance (Greenwood et al., 2011; Zucker, 1983). In her landmark investigation into institutional persistence, Zucker (1977: Experiment 3) compared participants acting individually to those placed in an organizational context, and she found the latter to be substantially more resistant to third-party influence attempts than the former. Extrapolating from this finding, I expect such a resistance effect stemming from the organizational context to be significantly stronger for decision-makers who highly identify with their organization than for those who identify only weakly. Given that strongly identifying actors tend to approach decision situations from the perspective of the organization (rather than from that of individuals making decisions on their own account) (Scott, 2014), previously made organizational decisions are perceived as higher on institutionalization and thus as less situation dependent and susceptible for change (Zucker, 1977). As a result, strong identification has the potential to outweigh isomorphic pulls of the field (Battilana \& Dorado, 2010). In other words, the feeling of belonging to and representing the organizational entity legitimizes distinctiveness and, to a certain extent, overrides concerns about field-level pressures (Binder, 2007; Greenwood et al., 2011), which ultimately explains nonconforming action. I thus expect strongly identifying decision-makers to display greater commitment to their organizations' practices and greater resistance to environmental pressures that challenge or offer alternatives to those practices, as per the following baseline hypothesis:

Hypothesis 1. There will be a positive effect of organizational identification on resistance to environmental pressures.

\section{Mediating Processes}

So far, I have argued that feelings of belonging to and representing the organizational entity create changes in decision-makers' tendencies to resist environmental pressures. But what specific cognitive attributes stemming from organizational identification are responsible for these behavioral differences? Zucker (1991) insisted that unpacking the cognitive processes involved in the maintenance and rejection of external institutions is a prime task for the micro-level approach to institutionalism. Notably, these cognitive processes constitute a critical missing part of an understanding of agency in the institutional theory framework (Zilber, 2002). Building on extant micro-institutional theorizing and enriching it with social psychological insights, I propose that organizational identification increases resistance to environmental pressures for two reasons: organizational identification (1) increases the decision-maker's certainty and (2) shapes the decision-maker's attention to the environment (as I elaborate in greater detail below). Consideration of the decision-maker's certainty and attention to the environment is consistent with the sequential decision-making model outlined by Tolbert and Zucker (1996), whereby organizational actors will first assess their own subjective situation as well as information from external sources, before making their choice. Moreover, social identity scholars propose that individuals' identification with an ingroup fundamentally shapes their perceived certainty and focus of attention (Turner, 1982, 1987). Taken together, certainty and attention serve as key social mechanisms linking individuals with their social systems and creating the fine-grained coupling between macro cause and micro effect that Bechky (2011) and Weber and Glynn (2006) have called for.

Certainty. A consistent finding in identity research is that decision-makers' subjective certainty is a positive function of social identification (e.g., Fransen, Haslam, Steffens, Vanbeselaere, De Cuyper, \& Boen, 2015; Mullin \& Hogg, 1998). Most notably, uncertainty identity theory (Hogg, 2000, 2007) suggests that identifying with a larger entity increases people's situational certainty in regard to who they are, what they should think, and how they should feel and behave. This is not only because identification with similar in-group members creates a strong sense of belonging and connection that raises people's self-esteem (Ashforth et al., 2008; Bergami \& Bagozzi, 2000; Fine \& Hallett, 2014; Pache \& Santos, 2013), but also because identification increases perceived coherence with the in-group and thus furnishes consensual validation of self (Fan \& Zietsma, 2017; George \& Chattopadhyay, 2005; Hogg \& 
Terry, 2000). Through categorizing themselves as prototypical group members, strongly identifying individuals perceive their own attitudes and judgments to be aligned with those of other group members, which bolsters their subjective certainty. Interestingly, this consensual validation effect through self-categorization operates even in settings where relatively little information about the group prototype is available; through selfanchoring, strongly identifying individuals will generalize attributes of self to the prototype based on the assumption of shared attributes due to common category membership (Cadinu \& Rothbart, 1996; Otten \& Epstude, 2006). In sum, identifying with a larger social entity can significantly increase certainty in decision-making.

Enhanced certainty, in turn, should increase decision-makers' resistance to environmental pressures. One of the central behavioral assumptions of institutional theory is that organizational decisionmakers have a strong preference for certainty (DiMaggio, 1988; Greenwood, Suddaby, \& Hinings, 2002; Oliver, 1991). Following a psychodynamic approach, institutional theory is attuned to decisionmakers' worries about failure and social disapproval and their corresponding need to create behavioral clarity and thus a comforting sense of security (Powell, 1991; Sturdy, 2004). Indeed, it has been suggested that a main reason why decision-makers give in to institutional pressures is because doing so may decrease their subjective uncertainty (Berger \& Luckmann, 1966). Conforming to institutionalized scripts that appear to reflect the perceived collective wisdom of the environment represents a common response to a state of uncertainty (DiMaggio \& Powell, 1983).

What is often made less explicit by institutionalists is the flipside of this argument. As decision-makers' subjective uncertainty decreases, so does their perceived need to follow external logics (Oliver, 1991, 1992). With growing confidence ${ }^{5}$ in their own judgments and greater clarity regarding how to behave in a certain situation, nonconformity with environmental institutions becomes an increasingly tenable approach for decision-makers to achieve organizational goals, thus increasing the degree of discretion assumed by the organization (Greenwood et al., 2011). As such, decision-makers'

\footnotetext{
${ }^{5}$ According to Sniezek (1992), "confidence” can be understood as quasi-synonymous with subjective certainty and can be formally defined as the strength of belief in the quality of one's judgment.
}

subjective certainty is a key mechanism explaining resistance to environmental pressures.

Together, then, the above arguments suggest that, to the extent that organizational identification creates certainty, it will also result in greater resistance to environmental pressures. In other words, because increased identification makes organizational decisionmakers more confident, these decision-makers will be less likely to resort to environmental conformity as a certainty enhancement strategy.

Hypothesis 2. Organizational identification has a positive effect on certainty, and certainty in turn has a positive effect on resistance to environmental pressures, such that certainty mediates the positive effect of organizational identification on resistance to environmental pressures.

Attention. Next, I offer the position that organizational identification affects the extent to which attention is oriented toward environmental stimuli. According to social identity theory, self-categorization as a member of a group modulates attention "in that it specifies who should and should not be attended to for appropriate information" (Abrams \& Hogg, 1990: 190). Specifically, strongly identifying individuals tend to reject information that threatens the local reality accepted by the in-group, particularly when that information originates from external sources outside of that in-group (Turner, 1982, 1987). The reason is that the more an individual identifies with a social entity, the less valid and relevant she will perceive information from outsiders to be. Strongly identifying individuals use the categorical membership of the information source as a heuristic cue for information appropriateness, such that the validity and relevance of out-group information are discounted (Mackie, Gastardo-Conaco, \& Skelly, 1992; Turner, 1987). As a result, out-group information will likely be dismissed and receive only minimal attention (Stapel, Reicher, \& Spears, 1994). Mackie and colleagues found empirical support for the notion that information from out-group members elicits relatively little attention and systematic processing (Mackie et al., 1992; Mackie, Worth, \& Asuncion, 1990). Consistent with this argument, I expect that decision-makers who strongly identify with their organization (i.e., the in-group) will pay less attention to cues from other actors in the organizational environment (i.e., the outgroup).

Just as environmental stimuli vary in the attention they receive from different decision-makers, so do their availability, accessibility, and salience during 
decision deliberation, and thus their ability to shape organizational behavior (Glaser, Fast, Harmon, \& Green, 2016; Nigam \& Ocasio, 2010; Thornton et al., 2012). Environmental pressures that are largely ignored have little potential to evoke meaning and define what is an appropriate course of action. On the other hand, environmental pressures that receive substantial attention from decision-makers are more likely to encounter critical reflection, influence sensemaking, and ultimately inform organizational action. For instance, if decision-makers devote significant resources to scanning and interpreting practice adoption decisions by other organizations in their field, these decisions will be more likely to shape those actors' own adoption choices, diminishing their likely resistance to mimetic pressures (Chandler \& Hwang, 2015; Fiol \& O’Connor, 2003). In short, responses to environmental pressures are substantially affected by the attention of organizational decision-makers to their institutional environment. Consequently, Thornton et al. (2012) viewed decision-makers' focus of attention as a crucial micro-level mechanism shaping organizational decisions vis-à-vis their institutional environment.

Taken together, these arguments suggest that organizational identification will lead decision-makers to devote less attention to environmental institutions, and reduced attention will, in turn, inhibit action toward adopting practices implied by the environment. Because attention to the external environment constitutes a necessary step toward conformity, reduced attention will buffer the organizational decisionmaker from environmental pressures.

Hypothesis 3. Organizational identification has a negative effect on attention, and attention in turn has a negative effect on resistance to environmental pressures, such that attention mediates the positive effect of organizational identification on resistance to environmental pressures. ${ }^{6}$

\section{The Role of Identity Content}

Beyond organizational identification, I suggest that the content of the organizational identity will shape decision-makers' focus of attention and, thus, the degree to which they resist environmental

\footnotetext{
${ }^{6}$ Note that, in a mediation model, the combination of a negative effect of the independent variable on the mediator and a negative effect of the mediator on the dependent variable means that the indirect effect of the independent variable through the mediator is positive.
}

pressures. Organizational identities vary in terms of the key attributes that members believe make the organization unique (Dutton \& Penner, 1993; Selznick, 1957). The content of the organizational identity provides guidance on what the organization is and how it and its members should behave (Glynn, 2000; Scott, 2014). The central, enduring, and distinct attributes of the organization thus function as referents for members when they act or speak on behalf of the organization (Dutton \& Dukerich, 1991; Fox-Wolfgramm, Boal, \& Hunt, 1998; Whetten, 2006). Further, fellow members of the organization are also expected to hold views that are in line with its identity (Fine \& Hallett, 2014). To achieve in-group consistency, the decision-maker will thus tend to adopt the underlying norms herself in order to avoid potential differences (Ridgeway, 2006; Thornton et al., 2012). Accordingly, the norms underlying organizational identity should lead the decision-maker to adopt the prototypical position.

Relevant identity claims may be expressed as mission statements, policies, and routines. These operate as the organization's enduring signature, providing members with a shared set of phenomenological points of reference that guide consequential deliberation and organizational decision-making (King et al., 2010; Whetten, 2006). Configurations of such identity claims can be usefully examined in terms of ideal types, with deliberate simplification affording comparative analysis to suggest testable hypotheses (Thornton \& Ocasio, 2008).

Building on the works of Parsons (1960), Etzioni (1961), and Albert and Whetten (1985), Gioia and Thomas (1996) identified two ideal-typical identity configurations, which I use in this article to derive a hypothesis regarding organizational identity content; these are "utilitarian identity" and "normative identity." A utilitarian identity is governed by values related to the maximization of profit and economic rationality. Obligations to the organization are defined in terms of self-interest, with remuneration and other extrinsic motivators as the major means of control over employees (Etzioni, 1961). The concept of normative identity, on the other hand, is typified by Parsons's (1960) pattern maintenance organization with primarily cultural, educational, and expressive functions. This church- or family-like identity underscores traditions, symbols, and values of altruism (Foreman \& Whetten, 2002), and members tend to emphasize the authenticity and expressive 
value of their outputs (Lamertz, Heugens, \& Calmet, 2005).

Comparing these two types, I propose members of an organization with a utilitarian (as opposed to a normative) identity will pay relatively greater attention to their external institutional environment. Thornton and Ocasio (1999), for example, documented how publishing houses increasingly following a logic of capitalism and profit maximization (cornerstones of a utilitarian identity) have shifted their focus to the organization's comparative market position. Perceiving their own legitimacy to be based on the organization's competitive position, decision-makers in these publishing houses increasingly directed the focus of their attention to external market needs (rather than just produce "good" books that would "sell themselves"). Along similar lines, the case study by Brown, Humphreys, and Gurney (2005) described a UKbased tour operator's utilitarian identity as evoking the need to devote constant attention to the market in order to remain competitive and achieve organizational goals. Likewise, Gioia and Thomas (1996: 381) cited the president of a university with a strongly utilitarian orientation as being "a great believer in peer comparisons," because such comparisons were seen as a key source of organizational learning and profitability. In their quantitative analyses, these authors found an association between a utilitarian (vs. normative) organizational identity and decision-makers favoring an offensive (vs. defensive) strategy that emphasizes diligent monitoring of external changes and an urge to be well informed about new programs. Therefore, I expect a utilitarian identity, with its strong focus on the organization's competitive position in its field, to lead decision-makers to pay greater attention to their external environment, which in turn increases the potential for pressures from this environment to shape behavior.

A normative identity, on the other hand, deemphasizes an external market orientation and directs attention away from environmental issues (Gioia \& Thomas, 1996). A normative identity has been found to foster commitment to the organization's ideals and create a kind of aesthetic autonomy (Moss, Short, Payne, \& Lumpkin, 2011). Members of organizations characterized by this type of identity tend to focus on intangible organization-internal capabilities as defining features and insulate themselves from organizational outsiders (Glynn, 2000). As such, individuals embedded in a normative identity will likely devote comparatively fewer cognitive resources to their environment, making them less prone to environmental pressures. ${ }^{7}$ Therefore:

Hypothesis 4. Resistance to environmental pressures will be stronger when the organizational identity is normative (vs. utilitarian), and this effect will be mediated by attention to environmental stimuli.

\section{METHODS}

\section{Study Overview}

This article uses three experimental studies to test the four hypotheses (see Table 1 for an overview). The first two studies build on a well-established experimental task (introduced by Berger \& Fisek, 1970). In each of several trials, participants have the opportunity to adjust their initial choice after learning about responses from competing participants. Focusing on those trials in which self and alter disagree, self staying with his/her previous choice is used as a measure of resistance to environmental pressures, the dependent variable in this research. The third study mirrors the structure of the first two but uses a slightly different task that introduces normative (rather than mimetic) pressures.

\section{Methodological Considerations}

As noted above, this article uses a set of experiments. Notwithstanding their limitations, experiments have the important advantage of controlling for extraneous factors that would be difficult to isolate in a field setting. By using random assignment and systematically varying theoretically relevant information, one can be confident that observed differences in the dependent variable are due to the manipulated features rather than to other factors, thus allowing for strong internal causal inference (Brewer, 1985; Thau, Pitesa, \& Pillutla, 2014; Webster \& Sell, 2007). No other methodology can establish causality - the gold standard of science-to the extent that experiments can. What is more, experiments can significantly enhance our understanding of underlying mechanisms that are often difficult to detect and isolate in contextually rich non-experimental field studies. It is not surprising,

\footnotetext{
${ }^{7}$ Note that I have no conceptual reason to believe, nor was I able to find any suggestive evidence pertaining to the notion, that, all other things being equal, a utilitarian identity ought to engender greater or lesser certainty (the second proposed mechanism underlying the identification-resistance effect).
} 
TABLE 1

Study Overview

\begin{tabular}{|c|c|c|c|c|c|c|}
\hline $\begin{array}{l}\text { Study } \\
\text { no. }\end{array}$ & $\begin{array}{l}\text { Hypothesis/-es } \\
\text { addressed }\end{array}$ & & erimental conditions & $\begin{array}{c}\text { Focal type of } \\
\text { environmental pressures }\end{array}$ & Mediators & Key findings \\
\hline 1 & $\mathrm{H} 1, \mathrm{H} 2, \mathrm{H} 3$ & $\begin{array}{l}(1) \\
(2)\end{array}$ & $\begin{array}{l}\text { Weak organizational } \\
\text { identification } \\
\text { Strong organizational } \\
\text { identification }\end{array}$ & Mimetic & $\begin{array}{l}\text { Certainty; } \\
\text { attention }\end{array}$ & $\begin{array}{l}\text { Organizational identification } \\
\text { increases resistance to } \\
\text { environmental pressures, and } \\
\text { this effect can be explained by } \\
\text { subjective certainty and attention } \\
\text { to environmental stimuli. }\end{array}$ \\
\hline
\end{tabular}

therefore, that experiments are increasingly becoming the go-to method for micro-institutional inquiry (see also Bitektine et al., 2018).

A possible source of concern regarding experimental methods may be the question of whether a laboratory setting can resemble a real-life organization. In considering this issue, it is important to bear in mind that experiments generalize to naturally occurring situations not directly but only through theory (Kanazawa, 1999; Lucas, 2003b; Martin \& Sell, 1979; Stolte, Fine, \& Cook, 2001; Zelditch, 1980). Therefore, an adequate experimental setting needs to ensure that the theoretical principles can be tested so that the results inform the underlying theory, which bridges the experimental study and the real world (Bitektine et al., 2018). Although institutional theory is often thought of as an innately macro-level approach, researchers have argued that, through sociological miniaturism (Stolte et al., 2001), predictions of institutionalism can also be applied to and tested at the level of smaller laboratory organizations (Zucker, 1991). In fact, previous work has successfully implemented experimental designs to study key aspects of institutional theory, including the institutionalization of abstract group standards (Zucker, 1977), the institutionalized perception of female leadership in organizations (Lucas, 2003a), and institutional processes leading to price bubbles (Levine, Apfelbaum, Bernard, Bartelt, Zajac, \& Stark, 2014; Levine \& Zajac, 2008), as well as consequences of institutional complexity (Raaijmakers,
Vermeulen, Meeus, \& Zietsma, 2015), different types of institutional logics (Glaser et al., 2016), and institutionalized belief systems (Hafenbrädl \& Waeger, 2017). Consistent with this line of research, I develop an experimental setting that fits the specific needs of the current investigation.

\section{Study 1}

Main task. The research problem required a situation in which participants are placed in "organizations" (defined here as "goal-directed, boundary-maintaining, and socially constructed systems of human activity”; Aldrich \& Rueff, 2006: 4) and make ambiguous decisions on behalf of their organization; moreover, it also required that they be confronted with information on others' behavior, in response to which participants could adjust their initial choice and emulate others' behavior (which allows for capturing variations in resistance to environmental pressures). Finally, participants should be task-oriented and should expect to be evaluated, so that they are motivated to perform the task well.

To establish such a setting, I used a variant of the standardized experimental situation first introduced by Berger and Fisek (1970). This approach is well established and has been shown to be applicable to the study of various sociological problems (Berger, 2007). Importantly, the standardized experimental situation is very similar to the designs used in earlier experimental research in institutional theory studying 
actors' responses to institutional pressures (Lucas, 2003a; Zucker, 1977) but has the advantage of being amenable to computerization. Computerization offers several well-known benefits, including the reduction of experimenter effects and greater control over timing (Molm, 2007).

More specifically, the task employed here required participants to undergo a series of ambiguous decision trials, in which they made binary choices on various organizational problems. Participants were told that their group was running a large flower shop and that they would need to make several strategic decisions for the shop on behalf of their group (more information on the group assignment appears below). For example, one of the questions read "Your group's flower shop needs to decide on the location for a new branch. Which of the following solutions do you choose?" The two options given were "open branch in a shopping mall" and "open branch downtown." I extensively pretested and refined these scenarios before arriving at a final list of 25 questions (see Appendix A for more details). These questions represent common strategic problems faced by real-life organizations, thus ensuring high levels of ecological validity (Lant \& Montgomery, 1992). In addition, the questions concern situations in which the material benefits associated with a structure are ambiguous and not readily calculable, consistent with Tolbert and Zucker's (1996) recommendations regarding adequate empirical contexts for institutional analysis. Finally, the questions were not overly complex, so as to ensure that even participants with limited in-depth knowledge about strategic management would be able to comprehend them (Wason, Polonsky, \& Hyman, 2002).

In each decision round, participants were first asked for their group's initial response. Subsequently, they were shown a response that they were told had been provided by a competing group. In reality, the competing group's responses were computer-generated to disagree with the participant's initial choice in the majority (i.e., 20) of the 25 trials, ${ }^{8}$ consistent with Foschi (1996). Environmental pressures were thus operationalized by confronting participants with evidence of peer groups having chosen the alternative response, which is consistent with the core idea behind mimetic isomorphismthat organizations feel pressured to adopt and replicate the solutions that others in their field have

\footnotetext{
${ }^{8}$ The following 20 trials were randomly chosen to have competitor disagreement: rounds 1, 3, 4, 5, 6, 7, 8, 9, 10, 12, $13,16,17,18,19,20,21,22,24$, and 25.
}

chosen (DiMaggio \& Powell, 1983)—as well as with earlier measures of environmental pressures used in archival research (Mizruchi \& Fein, 1999). ${ }^{9}$

After learning about the competing group's choice, participants had the opportunity to adjust their own group's initial response to provide a final choice for the respective trial. That is, participants could either resist the influence attempt $(1=$ stay with the initial choice) or conform to the influence attempt and imitate others ( $0=$ change the initial choice). Focusing on the 20 trials in which self and alter initially disagreed, self's behavioral response of staying with his or her original choice was used as a measure of resistance (Berger \& Fisek, 1970), the study's dependent variable. After reading the instructions, participants went through a practice trial that familiarized them with the structure of the task.

Participants and procedures. A total of 187 participants were recruited for a study on "decisionmaking" through the subject pool of the behavioral lab of a large public university. Participants were scheduled in groups $\left(M_{\text {session size }}=10.2\right.$ participants). To qualify for participation in the study, participants were required to have sufficiently high levels of English proficiency (as self-reported in the post-task questionnaire) and to demonstrate that they had paid sufficient attention to the study materials (as assessed based on the response to a screener question hidden in the post-task questionnaire). On the basis of these criteria, 18 people were excluded from the study, yielding a usable sample size of 169 participants (72\% were female, $M_{\text {age }}=21$ years $){ }^{10}$ Participants were randomly assigned to one of the two experimental conditions:

\footnotetext{
${ }^{9}$ The conceptualization of resistance to environmental pressures has certain similarities to the notion of escalation of commitment (Staw, 1976), in that both ideas have to do with organizational persistence (or the lack thereof). What makes the institutional theory-grounded concept of resistance different is its distinct focus on the organization's position vis-à-vis external forces, such as competitors' behaviors (Schreyögg \& Sydow, 2011).

${ }^{10}$ Specifically, two of the participants indicated their level of English language proficiency to be novice or less, while 16 participants responded incorrectly to the screener item "To show that you have read this question, please choose 0 (the very left button) as your response" (this item was adapted from Berinsky, Margolis, \& Sances, 2014, and was hidden within a number of other questionnaire items). I also ran the analyses including these 18 participants (i.e., with $n=187$ ), and the results were substantively similar.
} 
weak organizational identification $(n=84)$ or strong organizational identification $(n=85)$.

Upon arriving at the lab, participants were ushered into separate cubicles equipped with computers. A research assistant (who was blind to the study's hypotheses) obtained the participants' informed consent and told them they had to wait until all session participants had arrived before the experiment could start. Once the signal to begin was given, all further instructions were displayed on the computer screen in each participant's cubicle. Participants first underwent the identification manipulation before completing the study's main task and subsequently filling out a post-task questionnaire that included manipulation checks and other survey items. Finally, participants were debriefed and received U.S. $\$ 6.50$ as remuneration for their participation. The procedure took about 35 minutes to complete.

Manipulation. To vary organizational identification, I employed a variant of the well-established minimal group paradigm (introduced by Tajfel, Billig, Bundy, \& Flament, 1971), which uses categorization into a superordinate organization as the primary means for manipulating identification. ${ }^{11}$ The minimal group paradigm has the advantages of being compatible with ad hoc (as opposed to preexisting) groups and of not requiring potentially confounding face-to-face interaction between the group members. Even under these relatively strippeddown conditions, prior research has shown this conservative approach to be very effective in inducing identification (e.g., Brewer, 1979; Grieve \& Hogg, 1999). In particular, I adopted the organizational identification manipulation procedure devised by Doosje, Spears, and Koomen (1995) and Ellemers, Spears, and Doosje (1997), which has been recommended by Haslam (2004: Appendix 2) specifically for lab studies with ad hoc organizations. ${ }^{12}$ This manipulation procedure is described next.

The first phase of the procedure required participants to engage in a word and number association test, which ostensibly served the purpose of dividing

\footnotetext{
${ }^{11}$ The minimal group paradigm is consistent with Thornton et al.'s (2012: 79) view that social identification "can arise even in the absence of networks of interpersonal relations and interactions."

${ }^{12}$ The identification manipulation procedures adopted here feature several similarities to those used in the famous Robbers Cave study (Sherif, Harvey, White, Hood, \& Sherif, 1961), including group formation based on ostensible similarities and intergroup competition that increases group salience.
}

people into one of two groups that would later compete. The test presented participants with a series of key words (e.g., water) and key numbers (e.g., 1111), after which they were asked to choose one of four alternative responses they associated most with the key word (e.g., rain, fire, drink, or well) or with the key number (e.g., 1110, 1112, 111, or 4; see Appendix B for the full list of items used in the association test). Based on their responses, participants were led to believe that a computer algorithm would be able to assess their dominant thinking style and assign them to either the group of "inductive thinkers" or the group of "deductive thinkers" (in reality, all participants in all study conditions were assigned to the group of "inductive thinkers"). ${ }^{13}$ They were also told that each group consisted of four members who would compete against other groups on several tasks.

I then varied identification between conditions as follows. In the strong organizational identification condition, participants were told that the research team would like them to stay in the group to which they had been assigned for the rest of the study, and they were asked whether or not they would agree with this (which all but one participant did). This question was included because prior research has shown that voluntary group commitment enhances identification with a group (Turner, Hogg, Turner, \& Smith, 1984). In the weak identification condition, participants were simply informed that they would stay in their assigned group for the rest of the study, without being asked to voluntarily commit to doing so.

Afterward, participants in the strong organizational identification condition performed an intergroup reward allocation task, in which they allocated points using "Tajfel matrices" (Tajfel et al., 1971). These matrices provided 14 different payoff tuples for two individuals, with payoffs on one side of the spectrum benefitting the first person while hurting the second and payoffs on the other side benefitting the second person while hurting the first. In four of the six matrices, participants were asked to

\footnotetext{
${ }^{13}$ To explore whether people have differential associations with the two group labels, I had 40 MTurk workers rate their sentiments toward a group of deductive thinkers $(n=20)$ or a group of inductive thinkers $(n=20)$. Based on responses to an answer scale ranging from 1 (strongly negative) to 5 (strongly positive), I did not find a significant difference in sentiments toward deductive thinkers $\left(M_{\text {deductive thinkers }}=3.65\right)$ versus inductive thinkers $\left(M_{\text {inductive thinkers }}=3.60\right), t=0.25, d f=38, d=0.08$, $p>.10$.
} 
divide points between members of their own group (the inductive thinkers) and members of the other group (the deductive thinkers), whereas, in another matrix, the points were divided between two in-group members and, in another still, between two out-group members. ${ }^{14}$ Leyens, Yzerbyt, and Schadron (1994: 68) suggested that performing this intergroup reward allocation task increases category salience and thus identification. Participants in the weak organizational identification condition performed the same task but only after (rather than before) the study's main task.

Next, participants were asked to indicate, on a 9point scale, the extent to which they agreed with five general questions that directly or indirectly related to group membership or social contact (e.g., "Relationships with other people are very important to me"). ${ }^{15}$ After they had provided their responses, they were told that these five questions were "group involvement questions" that would, together with the participant's choices on the association test, allow for computing a personalized group involvement score-that is, a measure of the extent to which the participants felt involved with their respective group. It was deliberately left ambiguous how exactly this involvement score would be computed. Participants in the strong identification condition were then informed that their group involvement score was 53 points, which purportedly was significantly above the average score of 40 , whereas participants in the weak identification condition were told that their group involvement score was 27 points and thus significantly below the average score of 40 .

To analyze the effectiveness of the manipulation, I measured perceived identification using four items pertaining to the inductive thinkers in-group ("I identify with this group," "I do not fit in well with the other members of this group" (reverse coded), "I would like to get to know the other group members," and "I feel like I belong to this group"), anchored on a 9-point answer scale ranging from 1 ("strongly disagree") to 9 ("strongly agree"). The coefficient alpha $(\alpha=0.79)$ demonstrated sufficient reliability of the 4-item identification measure. Results of a oneway analysis of variance (ANOVA) showed that the mean of this measure among participants in the strong identification condition $\left(M_{\text {strong identification }}=\right.$ 6.29 ) was significantly greater than the mean among

\footnotetext{
${ }^{14}$ See Appendix $\mathrm{C}$ for a list of the Tajfel matrices used in the intergroup reward allocation task.

${ }^{15}$ See Appendix D for all five "group involvement questions."
}

participants in the weak identification condition $\left(M_{\text {weak identification }}=5.60\right), F(1,167)=11.69, d=0.53$, $p \leq .001$. As a supplementary behavioral manipulation check, I also compared the number of points allocated to in-group members in the reward allocation task (focusing on the four trials of the reward allocation task in which participants were asked to divide points between members of their own group and members of the other group) and found that significantly more points were allocated to in-group members in the strong identification condition $\left(M_{\text {strong identification }}=38.55\right)$ than in the weak identification condition $\left(M_{\text {weak identification }}=29.80\right)$, $F(1,167)=7.61, d=0.42, p \leq .01$. This result provided further behavioral support for a successful manipulation. Appendix E offers details on the comprehension and suspicion checks that were conducted.

Main effect. Because participants completed 20 relevant individual rounds of the decision task, I computed an average proportion of stay decisions across these trials to capture the dependent variable of resistance.$^{16}$ A one-way ANOVA revealed significant differences in resistance across conditions, $F(1,167)=$ 10.44, $d=0.50, p \leq .01 .{ }^{17}$ Participants in the strong identification condition were more resistant $\left(M_{\text {strong }}\right.$ identification $=0.89$ ) compared to participants in the weak identification condition $\left(M_{\text {weak identification }}=\right.$ 0.81), providing empirical support for Hypothesis 1.

Mediational analyses. Hypotheses 2 and 3 stated that the effect of organizational identification on resistance to environmental pressures is mediated by the decision-maker's certainty (Hypothesis 2) and attention to environmental stimuli (Hypothesis 3), such that organizational identification increases certainty but decreases attention to environmental stimuli, both of which, in turn, affect resistance. "Subjective certainty" can be formally defined as the strength of belief in the quality of one's judgments (e.g., Sniezek, 1992). It was measured at the participant level in the post-task questionnaire using the following three items (with an answer scale ranging from 1, "strongly disagree," to 5, "strongly agree"): "I feel confident about my responses," "I feel confident about being a participant in the experiment," and "I found it easy to provide appropriate responses" (see

\footnotetext{
${ }^{16}$ As an alternative to averaging the responses across trials, I also conducted random intercept logistic regressions with participant as clustering variable (RabeHesketh \& Skrondal, 2012). The results of these analyses are consistent with those reported in the article.

${ }^{17}$ In the article, I report the results of ANOVAs, but all findings are robust to using Tobit regressions instead.
} 
Sniezek, 1992, and Zucker, 1977, for similar items). The measure demonstrated good psychometric properties $(\alpha=0.82)$.

Attention can be captured by considering the time allocated to processing information from a source (e.g., Dutton, 1986: 4). Consistent with this approach, attention was proxied at the trial level using the behavioral measure of reaction time (Prinzmetal, McCool, \& Park, 2005) for the second-stage decision in the individual trials of the main task, indicating the degree to which the participant paid attention to the competing group's choices (with greater attention being reflected by longer reaction times). While I acknowledge that reaction time is a composite measure of a number of unobserved mental processes, it is well aligned with the (similarly multifaceted) concept of attention, and specifically with its subprocess of executive attention, which is central to organizational decision-making and involves the allocation of cognitive resources in working memory to incoming schema-inconsistent stimuli (Ocasio, 2011). Although the duration of the second-stage decision presumably also encompasses the process of indicating the group's final choice, in addition to processing the competitor's response, it is reasonable to assume that participants who completed Stage 2 quickly have not paid much attention to whatever their competitor's choice was, whereas those that spent considerable time on this screen have tried to make sense of the response from the competitor. Since reaction times (measured in seconds) were highly skewed, I redefined the variable using a logarithmic transformation. I then created an average across the 20 trials for each participant.

I began testing Hypotheses 2 and 3 by running two simple mediation bootstrapping tests (Preacher \& Hayes, 2004; the mediation tests were run with 5,000 bootstrap samples using version 2.16 of the PROCESS macro in SPSS; Hayes, 2013), in which each of the two potential mediators was analyzed independently (Hayes, 2013: Model 4). The indirect effect of identification on resistance was positive and significant for certainty $(\hat{a} \hat{b}=0.019 ; 95 \%$ confidence interval (CI) [0.005, 0.042]), as was the indirect effect in the mediation model for attention $(\hat{a} \hat{b}=0.029 ; 95 \%$ CI $[0.008,0.057])$. Following Preacher and Kelley (2011), I also report the completely standardized indirect effects as measures of effect size; these were $\hat{a} \hat{b}_{\mathrm{cs}}=0.065$ for certainty and $\hat{a} \hat{b}_{\mathrm{cs}}=0.101$ for attention.

I then examined both factors simultaneously in a single multiple mediators model (Hayes, 2013: Model 6). Estimation results for this model showed that the two parallel indirect effects were statistically significant (via certainty: $\hat{a} \hat{b}=0.017 ; 95 \%$ CI $[0.005$, $0.036] ; \hat{a} \hat{b}_{\mathrm{cs}}=0.059$; via attention: $\hat{a} \hat{b}=0.027 ; 95 \%$ CI $\left.[0.005,0.055] ; \hat{a} \hat{b}_{\mathrm{CS}}=0.094\right)$. However, the serial indirect effect through both certainty and attention was not found to be significant $(\hat{a} \hat{b}=0.002 ; 95 \%$ CI $\left.[-0.005,0.013] ; \hat{a} \hat{b}_{\mathrm{cs}}=0.006\right)$. Finally, the total indirect effect (i.e., the sum of the three specific indirect effects described above) was statistically significant in this model $(\hat{a} \hat{b}=0.046 ; 95 \%$ CI [0.020, 0.079 ]; $\left.\hat{a} \hat{b}_{\mathrm{cs}}=0.159\right)$. Figure 1 shows the estimates for the individual direct effects in the multiple mediators model. It is worth noting that the direct effect of identification on resistance was positive but no longer significant once certainty and attention were included as covariates, indicating full (Baron \& Kenny, 1986) or indirect only (Zhao, Lynch, \& Chen, 2010) mediation. A correlation table for this and the other studies reported in this paper is provided in Appendix F (Tables F1-F3). Three supplementary post hoc analyses exploring gender effects, temporal tendencies, and measure validity are summarized in Appendix G.

Discussion. The results of Study 1 provided support for Hypotheses 1 to 3 . As predicted, I found a significant main effect of organizational identification on resistance to environmental pressures, with greater resistance in the strong than in the weak identification condition. Further, Study 1 provided important insights into the theoretical processes responsible for the observed main effect. Specifically, in line with Hypotheses 2 and 3, both decision-maker certainty and attention to environmental stimuli mediated the identification-resistance relationship. In sum, the results of Study 1 contribute to understanding how organizational identification influences cognition and affects the way decisionmakers respond to pressures from the environment.

\section{Study 2}

Designed to test Hypothesis 4, Study 2 uses the experimental procedures of the strong identification condition in Study 1 while adding identity content to the manipulation by requiring participants to contribute to a mission statement for their group. Organizations frequently codify their identity claims in their mission statements, which gives employees a sense of meaning and guides the actions of the organization (Leuthesser \& Kohli, 1997; Pearce \& David, 1987). In this experiment, mission statements serve to activate and increase the salience of preexisting understandings of normative and utilitarian 


\section{FIGURE 1}

\section{Study 1: Results of the Mediation Analyses}

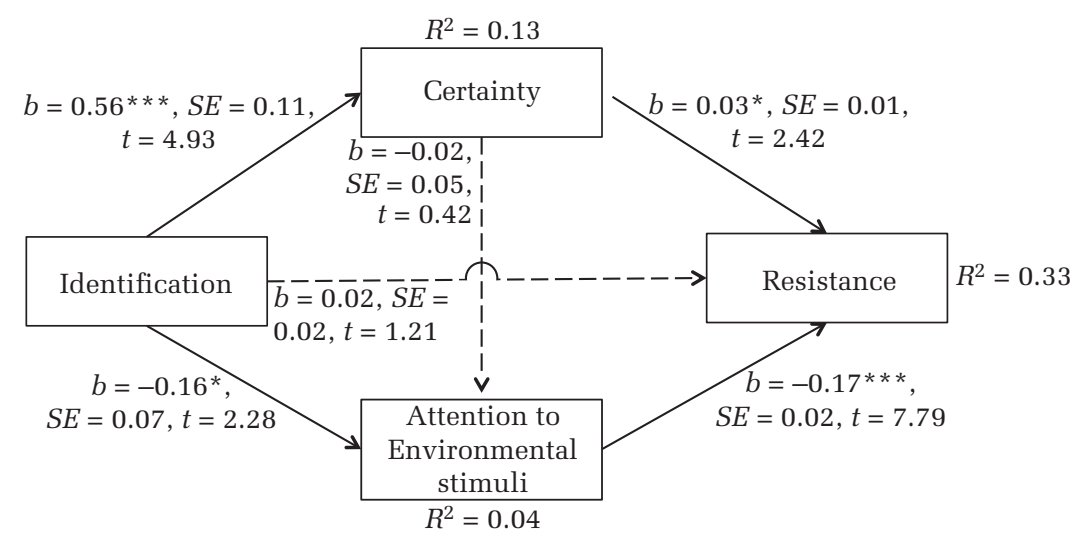

Notes: $n=169$. Strong identification was coded as 1 , and weak identification was coded as 0 . The statistics indicate direct effects from the multiple mediators model. Asterisks indicate significant coefficients.

$\begin{aligned} * & \leq .05 \\ * * * & \leq .001\end{aligned}$

logics stored in individuals' memories (Higgins, 1996; Thornton et al., 2012). Using mission statements to operationalize identity type is particularly consistent with the social actor view on identity (Whetten, 2006; Whetten \& Mackey, 2002), ${ }^{18}$ which emphasizes that organizations make overt "claims" about who they are in society and that such claims have a profound influence not only on external but also on internal audiences.

Participants and procedures. The participants for this study included 180 business major undergraduate students at a large public university. Students participated in exchange for U.S. \$6.50 and course credit. As in Study 1, self-reported levels of English proficiency and an attention screener question were used to exclude, in this case, seven people from the study, resulting in a usable sample size of 173 participants ( $51 \%$ were female, $M_{\text {age }}=21$ years). Participants were randomly assigned to either the utilitarian identity condition $(n=92)$ or the normative identity condition $(n=81)$. Except for the manipulation, the procedures and materials were identical to those of the strong identity condition in Study 1.

Manipulation. After finishing the practice trial of the flower shop task, participants were informed that, like any other organization, their flower shop needed a "mission statement," which was defined as a coherent business purpose that is both central and distinctive. To craft such a mission statement, each

\footnotetext{
${ }^{18}$ For more details on the prevalent views on organizational identity, see Gioia et al. (2013).
}

participant was told that all group members would need to contribute one sentence and that he or she would be the last member of the group to do so. Before adding their own sentence, participants in the normative identity condition were shown the following statements, ostensibly contributed by the other members of their team (these statements build on the work of Gioia \& Thomas, 1996): "Superior quality (rather than competitive performance) is what makes us unique," "Our strategy is based on what we ourselves consider to be the right way of doing business (rather than what the competitive market might reward the most)," and "What motivates our business is that we do what we believe is right for us (even if it's not always the most profitable course of action)." Conversely, participants in the utilitarian identity condition were exposed to the following team member statements: "Superior competitive performance (rather than quality, etc.) is what makes us unique," "Our strategy is based on what the competitive market values and rewards the most (rather than what we ourselves might consider to be the right way of doing business)," and "What motivates our business is that we are highly profitable (even if this means changing our ways)." Subsequently, participants in both conditions were required to complete the sentence "When we make decisions, we primarily take into consideration..." by choosing between two alternatives: “... our own assumptions, traditions, and ideology (rather than competitive information)" or "... the objective information that is available from the competitive 
environment (rather than specific assumptions, traditions, or ideologies)." ${ }^{19}$ They were encouraged to select the sentence that would be consistent with what the other team members had entered before them. Appendix $\mathrm{H}$ summarizes the manipulation checks for Study 2.

Main effect. Results of a one-way ANOVA showed that resistance averaged across trials was significantly greater in the normative identity condition $\left(M_{\text {normative identity }}=0.92\right)$ than in the utilitarian identity condition $\left(M_{\mathrm{utilitarian}}\right.$ identity $\left.=0.87\right), F(1$, $171)=4.69, d=0.33, p \leq .05$. These results provided empirical support for Hypothesis 4.

Mediational analyses. I then tested whether the observed identity type effect was mediated by attention to environmental stimuli, also including the decision-maker's certainty as a second potential mediator in the analysis. I used the same 3-item measure for certainty that I employed in Study 1 $(\alpha=0.84)$ and again used the national logarithm of reaction time to gauge attention.

A multiple mediators model (Hayes, 2013: Model 6) showed that the indirect effect of identity type on resistance via attention was statistically significant $(\hat{a} \hat{b}=$ 0.007; 95\% CI [0.001, 0.021]; $\hat{a} \hat{b}_{\mathrm{cs}}=0.029$ ). However, the indirect effect via certainty was not significant ( $\hat{a} \hat{b}=0.000 ; 95 \%$ CI $\left.[-0.010,0.008] ; \hat{a} \hat{b}_{\mathrm{cs}}=-0.002\right)$, nor was the serial indirect effect through both certainty and attention $(\hat{a} \hat{b}=0.000 ; 95 \%$ CI $[-0.001$, 0.001]; $\hat{a} \hat{b}_{\mathrm{cs}}=0.000$ ). Finally, the total indirect effect lacked statistical significance $(\hat{a} \hat{b}=0.007 ; 95 \%$ CI $\left.[-0.005,0.021] ; \hat{a} \hat{b}_{\mathrm{cs}}=0.027\right)$. Figure 2 summarizes the estimates for the individual direct effects in the multiple mediators model, and Appendix I describes a post hoc analysis pertaining to gender effects.

Discussion. The results of Study 2 extended those of the previous study by showing that the type of identity matters, as participants in the normative identity condition were significantly more resistant to environmental pressures than were participants in the utilitarian identity condition. Mediation analyses

\footnotetext{
${ }^{19}$ To validate the eight statements used for the utilitarian/normative identity manipulation, I provided definitions of the two identity types to 40 MTurk workers and had them rate each statement on a bipolar scale ranging from 1 (utilitarian) to 9 (normative). Results confirmed my a priori classification of the items. A paired sample $t$ test showed that the mean across the four utilitarian identity statements was significantly smaller $(M=2.73$, $S D=1.79$ ) than the mean across the four normative identity statements $(M=6.52, S D=1.51)$, mean diff. $=3.79, t=$ 8.13, $d=1.29, p \leq .001$.
}

indicated that this was due to differences in the attention that participants paid to environmental stimuli.

\section{Study 3}

The environmental pressures on which Studies 1 and 2 focused emphasized mimetic processes leading to conformity. Another important way in which institutions can exert themselves on organizational decision-makers is through normative pressures (DiMaggio \& Powell, 1983). To investigate whether the findings related to identity type generalize to these sorts of pressures, I conducted an additional study. Study 3 builds on the structure of Study 2 but employs a different task that introduces normative pressures. Moreover, Study 3 introduces a control condition in addition to the normative and utilitarian identity conditions. Finally, Study 3 uses a nonstudent sample.

Main task. Normative pressures are imposed through field norms that specify how things are done (Scott, 2014). One particularly common and important source of normative pressures are industry standards established by professional organizations that define appropriate behavior (Berrone, Fosfuri, Gelabert, \& Gomez-Mejia, 2013; Greenwood et al., 2002; Rossman \& Schilke, 2014). Study 3's main task focused on one particular standard established by the International Organization for Standardization (ISO), the world's largest developer of industry standards (Helms, Oliver, \& Webb, 2012). This particular standard-ISO 31000lays out certain codified procedures for organizational risk management. In the task, participants were asked to read some basic background information as well as a list of pros and cons related to the standard (for the full text of the vignette, please see Appendix J) and then to respond to two items, which asked them to indicate their support for adopting ISO 31000 for their flower shop ("Our flower shop is going to use ISO 31000 as a guide to integrate risk management in our company" and "Our flower shop is going to invest in ISO 31000 adoption training," anchored on a 9-point scale ranging from 1, "totally disagree," to 9, "totally agree"). The two-items were reverse-coded and averaged to capture participants' resistance to normative pressures.

Participants and procedures. The participants included 531 adults recruited via Amazon Mechanical Turk (MTurk), an online crowdsourcing service offering large volumes of small web-based tasks to anonymous online workers for monetary compensation (for further details about MTurk and analyses that confirm the quality of MTurk responses, see Buhrmester, Kwang, \& Gosling, 2011, and Weinberg, Freese, \& McElhattan, 2014). Participants were paid 


\section{FIGURE 2}

\section{Study 2: Results of the Mediation Analyses}

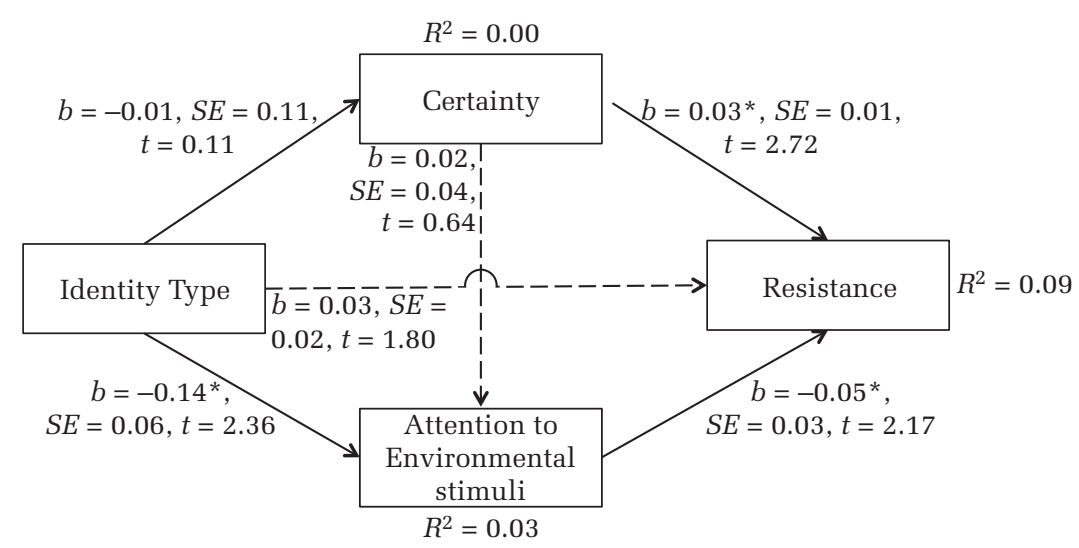

Notes: $n=173$. Normative identity was coded as 1 , and utilitarian identity was coded as 0 . The statistics indicate direct effects from the multiple mediators model. Asterisks indicate significant coefficients.

${ }^{*} p \leq .05$

U.S. $\$ 1$ for an online study that took about $10 \mathrm{~min}-$ utes to complete. An attention screener question was used to exclude 25 people from the study, yielding a usable sample size of $n=506 .{ }^{20}$ Within that sample, $48.0 \%$ of participants were female, and they were 36.6 years old on average $(S D=11.8)$, with an average of 14.6 years of full-time work experience $(S D=$ 11.1). To assess the degree to which participants had relevant first-hand experience with organizational decision-making, I included the following question: "Have you ever run an organization or organizational unit-no matter how large or small—such that you personally had a significant say in its key strategic decisions?" Of the participants, 56\% answered "yes" to this question. ${ }^{21}$ Participants were randomly

\footnotetext{
${ }^{20}$ In Study 3, the attention screener included in the posttask questionnaire asked participants what type of product the company they were representing in the main task was primarily offering (with answer choices being food, medical devices, and flowers).

${ }^{21}$ Those participants who indicated they did have organizational decision-making experience were subsequently asked to provide more details about the organization and their job. The median number of employees in these organizations was 10, suggesting that most organizations that participants were in charge of were rather small. Inspection of freely entered text describing the main industry showed that many of these organizations were in the fields of retail, information technology, education, and miscellaneous services. Self-reported job titles included coowners, managers, supervisors, and consultants.
}

assigned to either a control condition $(n=170)$, a utilitarian identity condition $(n=172)$, or a normative identity condition $(n=164)$. Participants underwent the manipulation, completed the main task, and responded to a brief post-task survey; they were then given a code to be entered in MTurk in order to receive their compensation.

Manipulation. Study 3 used the manipulation of organizational identity type employed in Study 2 while adding a third control condition in which no identity manipulation took place. To keep the length of the study approximately constant, participants in this control condition still completed the association test and the reward allocation task, but without any reference to group formation (specifically, in this condition, the association test ostensibly served the purpose of evaluating participants' personal style of thinking, the reward allocation task only referred to anonymous study participants rather than in-group/ out-group members, and participants did not contribute to or learn about a mission statement). Participants in the control condition were only informed right before the main task that they were being assigned to a group with three other randomly chosen participants that would need to make organizational decisions together. Appendix K demonstrates the effectiveness of the manipulation.

Main effect. Results of an ANOVA showed that resistance $(\alpha=0.96)$ was significantly different across the three conditions, $F(2,503)=11.07, \eta^{2}=$ $0.04, p \leq .001$. Resistance was significantly greater in 
the normative identity condition $\left(M_{\text {normative identity }}=\right.$ $5.67)$ than in the utilitarian identity condition $\left(M_{\mathrm{utilitarian}}\right.$ identity $=4.52), F(1,334)=18.47, d=0.47, p \leq .001$, in further support of Hypothesis 4. Additionally, in the control condition, resistance $\left(M_{\text {control }}=4.71\right)$ was significantly smaller than in the normative identity condition, $F(1,332)=13.94, d=0.41, p \leq$ .001 , but not significantly different than in the utilitarian identity condition, $F(1,340)=0.55, d=$ $0.08, p>.10$.

Mediational analyses. Certainty was measured using the 3-item scale employed previously $(\alpha=$ 0.90). Similar to the previous studies, attention was captured by the natural logarithm of the time spent reading about the ISO standard. I first conducted mediation analyses using a multicategorical independent variable (control, utilitarian identity, normative identity) and the unweighted contrast coding approach described by Hayes and Preacher (2014) and implemented in the PROCESS script (Hayes, 2013: Model 4). ${ }^{22}$ The model with certainty as mediator showed that the control condition relative to the two identity conditions combined did not have a significant indirect effect on resistance through certainty ( $\hat{a} \hat{b}=-0.025 ; 95 \%$ CI $[-0.113$, 0.028]), nor was this indirect effect through certainty significant for the contrast comparing the two identity conditions $(\hat{a} \hat{b}=0.011 ; 95 \%$ CI $[-0.010$, 0.078]). ${ }^{23}$ Moreover, in the model with attention as mediator, the control condition relative to the two identity conditions combined did not have a significant indirect effect on resistance through attention $(\hat{a} \hat{b}=-0.036 ; 95 \%$ CI $[-0.153,0.061])$. However, this indirect effect through attention was statistically significant for the utilitarian versus normative identity contrast ( $\hat{a} \hat{b}=0.127 ; 95 \%$ CI [0.028, 0.263]).

Further, a multiple mediator model using a binary independent variable contrasting the utilitarian and normative identity conditions (Hayes, 2013: Model 6) showed that the indirect effect of identity type on resistance via attention was statistically significant ( $\hat{a} \hat{b}=0.139 ; 95 \%$ CI $\left.[0.035,0.310] ; \hat{a} b_{\mathrm{cs}}=0.027\right)$. However, the indirect effect via certainty was not significant $(\hat{a} \hat{b}=0.003 ; 95 \%$ CI $[-0.031,0.067]$;

\footnotetext{
${ }^{22}$ For multicategorical independent variables, the PROCESS script currently does not accommodate multiple mediator models (Hayes, 2013: Model 6). To probe serial mediation, I separately estimated a multiple mediator model for the two identity conditions only (see below).

${ }^{23}$ The effect size option is currently not available in the PROCESS script with multicategorical independent variables.
}

$\hat{a} \hat{b}_{\mathrm{cs}}=0.001$ ), and nor was the serial indirect effect through both certainty and attention $(\hat{a} \hat{b}=-0.004$; 95\% CI [-0.026, 0.002]; $\left.\hat{a} \hat{b}_{\mathrm{cs}}=-0.001\right)$. Finally, the total indirect effect was statistically significant $(\hat{a} \hat{b}=$ $0.138 ; 95 \%$ CI $\left.[0.024,0.320] ; \hat{a} \hat{b}_{\mathrm{cs}}=0.027\right)$.

Figure 3 summarizes the estimates for the direct effects in the multiple mediators model. The main effect of identity type on resistance was statistically significant in this model, suggesting partial mediation. Appendix L reports the results of post hoc analyses exploring the roles of gender and task experience.

\section{GENERAL DISCUSSION}

This article suggests that organizational identity processes can significantly affect institutional action, providing a novel impetus for adding identity to the list of key concepts that help explain variations in responses to environmental pressures and withinfield heterogeneity. The findings have broad theoretical significance because they offer new support for the claim that micro-level cognition plays a critical role in how decision-makers respond to macroinstitutional pressures, thus giving new insight into the questions of why some organizational decisionmakers may resist institutional pressures while others do not and, as a result, why not all organizations are the same. The article's findings contribute to the literature in several ways.

First and foremost, this research promotes the development of the microfoundations of institutional theory called for by Zucker (1991), Powell and Colyvas (2008), and many others (e.g., Bitektine \& Haack, 2015; Greenwood et al., 2011; Thornton et al., 2012). This emerging literature asks the important question of how individuals' location in social relations affects the way in which they interpret and respond to their institutional context (Glaser et al., 2016; Powell \& Colyvas, 2008). Deviating from traditional neo-institutional theory, microinstitutionalism thus places great emphasis on intra-organizational processes to better understand differences in the behavior of organizations (Gavetti et al., 2007; King et al., 2010; Zucker, 1983). My findings augment this work and indicate the importance of organizational identification as a key source of variation in how organizational decision-makers interact with their external context. I offer initial experimental support for the notion that organizational identification has a significant influence on a key institutional outcome variable-resistance to environmental pressures. Adding greater nuance to 


\section{FIGURE 3}

\section{Study 3: Results of the Mediation Analyses}

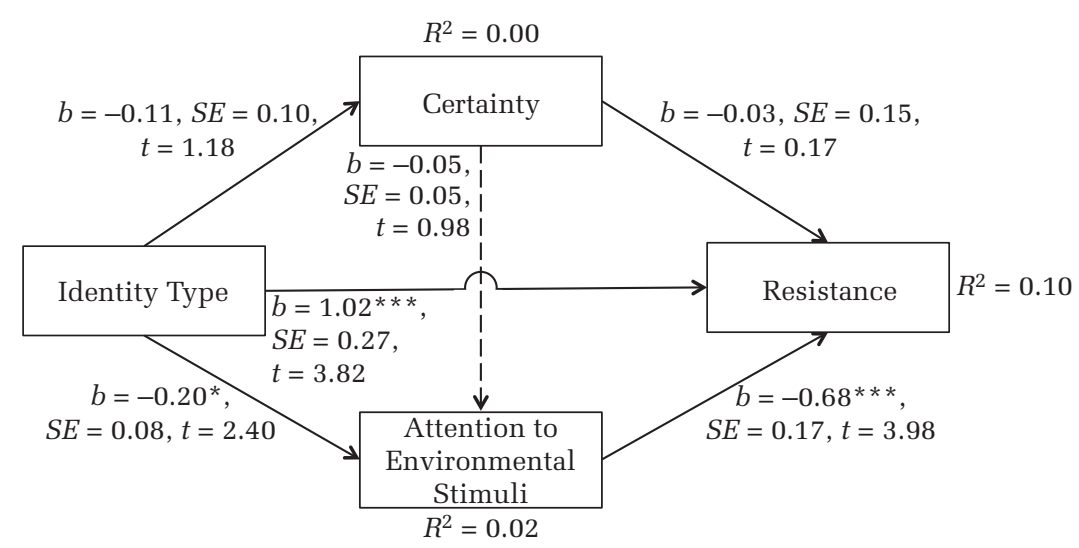

Notes: $n=336$. Normative identity was coded as 1 , and utilitarian identity was coded as 0 . The statistics indicate direct effects from the multiple mediators model. Asterisks indicate significant coefficients.

${ }^{*} p \leq .05$

$* * * p \leq .001$

our understanding of the cognitive processes through which the local context shapes organizational decision-making, the article recognizes two mechanisms-certainty and attention to environmental stimuli-that explain the identificationresistance effect. Identifying these mechanisms equips institutional theory to move beyond the notion of blind imitation to capture more nuanced adoption processes that explain why some decisionmakers give in to environmental forces while others are able to resist them. The article thus contributes both novel empirical evidence and additional theoretical richness to the micro-institutional research agenda. In particular, it provides support for a situated stance (Boxenbaum, 2014), highlighting that the repertoire of practices an organization comes to adopt is materially affected by the nature of decisionmakers' relationships with their organization. Organizations' tendencies to succumb to or resist to institutional pressures may thus arise not only from features of the environment but also from key decision-makers' sense of connection to the organization, as well as from fundamental characteristics that are shared among organizational members. From this perspective, organizational identity constitutes an important enabling condition for organizational agency. Conceptualizing the degree of agency as a continuous (rather than binary) concept, this paper advocates that organizational actors are likely to fall somewhere in between the two extremes of heroic actors and institutional dopes, depending on their degree of identification and the type of identity, thus advancing a much-needed, contingent middle ground concerning agency within institutional theory (Battilana, 2006; Battilana \& D'Aunno, 2009; Hwang \& Colyvas, 2011; Powell \& Bromley, 2015).

Further, the article makes a methodological contribution by re-incorporating experimental techniques into institutional analysis and helping to revive the experimental approach to institutional theory initiated 40 years ago by Zucker (1977). The unfortunate lack of methodological diversity in the institutional line of research has restricted it to specific kinds of research questions while leaving others unanswered. For too long, a rigid dichotomy of "macro = quantitative/explanatory" and "micro = qualitative/interpretative" has persisted and confined institutional research to an unnecessarily limited interpretation of institutions. Experimental methods help to break away from this false dichotomy and bring useful new explanatory perspectives to the micro-level study of institutions and their effects, thus opening up a whole new array of topics accessible to institutionalists. For example, the experimental approach has the potential to make significant contributions to explaining how groups of individuals organize and carry out their goals (Heath \& Sitkin, 2001) and to clarifying causal effects of micro-level process (Bitektine, 2011; Brewer, 1985; Raaijmakers et al., 2015; Webster \& Sell, 2007), thus allowing for an approach to institutionalism from the bottom up and complementing 
existing insights. In my particular investigation, using an experimental design enabled me to study how institutions specifically impact ambiguous organizational decisions, which then allowed me to advance my broader theoretical argument for agency as a contingent continuum. Further, experiments like the ones reported here can give unique insights into relevant theoretical mechanisms (such as certainty and attention) that help to explain how organizational decision-makers perceive and react to institutional pressures. Such mechanisms are fundamental to theory building and enrichment (Stinchcombe, 1991) but are often difficult to detect and isolate in contextually rich field studies, which may be why they have so far gone untested in such studies (David \& Bitektine, 2009; Kennedy \& Fiss, 2009; Thornton et al., 2012). Moving from inside the organization to external audiences, future experiments also have huge potential to enrich the study of legitimacy perceptions, a key construct in institutional theory that too often is merely assumed rather than directly measured and linked to relevant cognitive processes (Haack et al., 2016). Experiments can thus add considerable richness to the institutional research agenda, following a sociological miniaturism approach to institutionalism, whereby large-scale social issues are investigated by means of small-scale social situations (see Stolte et al., 2001, for more details on sociological miniaturism). In sum, experimental methods should help to expand the "resource space" of potential contributions available to the institutional research community and help the institutional paradigm to remain vibrant (Bitektine, 2009; Bitektine \& Miller, 2015). Specifically, the current article's findings show that an experimental manipulation can successfully induce different levels of identification and, in turn, certainty, attention, and resistance to environmental pressures. It is my hope that these findings, along with the procedures and measures employed, help to pave the way for future micro-quantitative work in institutional theory.

Finally, the article also makes an integrative contribution (Okhuysen \& Bonardi, 2011) by further synthesizing the highly complementary but thus far too-often separated streams of institutional and identity research. Despite their common foundation in social constructionism and Durkheim's theory of meaning, these two lines of research have evolved largely independently (Pedersen \& Dobbin, 2006), with relatively little cross-fertilization (but see Glynn, 2008, and Kroezen \& Heugens, 2012). An integrative approach provides significant theoretical leverage by allowing for the construction of meaning to take place both within fields and within organizations. It thus enables a richer and more complete approach to understanding organizational decisionmaking-one that may help to reconcile the seemingly contradictory observations of homogeneity and distinctiveness that are central to the two literatures. While recent progress has been made in better understanding how the institutional environment may shape an organization's identity, the current work complements these efforts by suggesting how an organization's present identity affects its responses to environmental pressures (see Besharov \& Brickson, 2016). In this way, the article underlines how identity theory can add to institutional theory the insightful notion of organizations as filters of external institutional pressures. It is through this filtering role that organizations themselves can open up room for actorhood in a way that is orthogonal to the choices of decision-makers. Such a position is highly compatible with an organizations-as-institutions perspective (Greenwood et al., 2011; Zucker, 1983), whereby the complexity created through the interplay between environmental and organizational practices provides greater potential for discretion and flexibility. All this implies that previous discussions of enabling conditions of actorhood, which were usually located in either the individual decision-maker or the organizational environment, must be augmented to accommodate the organization itself. ${ }^{24}$

In addition to its scientific merit, this research speaks to an issue of high practical importance. Especially in times of great environmental uncertainty (e.g., during an economic crisis), many organizations tend to give up some of their agentic qualities and almost automatically adopt certain institutional practices in order to "play it safe." However, as previous research has shown, conformity with the environment is not always exclusively beneficial; while it may improve symbolic performance by increasing legitimacy, it can also hurt technical efficacy and differentiation-based competitive advantage (Barreto \& Baden-Fuller, 2006; Meyer \& Rowan, 1977; Zucker, 1987). Thus, organizations may benefit from proactive management of environmental conformity versus resistance. My investigation suggests (but certainly does not conclusively prove) that one way to do so may be to steer identity salience and content. While an

\footnotetext{
${ }^{24}$ I am grateful to one of the anonymous reviewers for generously sharing this thought.
} 
organization's identity has traditionally been thought to be rather enduring (Albert \& Whetten, 1985), others have argued that it may be more malleable (Gioia, Schultz, \& Corley, 2000) and have pointed to several communication- and socialization-based approaches to identity adaptation (Battilana \& Dorado, 2010; Harquail, 2006). Moreover, whenever the organizational goal is to implement practices that challenge traditional models that are well established in an organizational field (Battilana, 2006), selecting leaders who strongly identify with their organization may be particularly advisable.

Although this research sheds new light on the link between organizational identity processes and resistance to environmental pressures, it is limited, like prior studies, by its conceptual focus and the methods employed. These limitations open up important avenues for future research. For example, the article clearly focuses on the consequences of organizational identity while largely bracketing the question of how identity is constructed. In doing so, it adopts an embedded agency perspective while neglecting reproduction and transformation from the bottom up (Steele \& King, 2011; Thornton et al., 2012). Clearly, further research is needed to elucidate the duality of organizational identity and institutionalized decision-making (Kroezen \& Heugens, 2012).

Moreover, this investigation takes the common but somewhat simplistic theoretical approach of individual decision-makers representing organizational actors (King et al., 2010), thus implicitly framing the organization as a reflection of its individual members (Hambrick \& Mason, 1984: 193). In many cases, the process of aggregation can be considerably more complicated than a linear pattern, and further insight is needed to understand how mechanisms such as social interaction and interdependencies affect emergent organization-level outcomes. Qualitative methods and agent-based modeling seem particularly promising for extending the current investigation to study both how institutional pressures are enacted through ongoing interactions with other organizational members and how collective organizational actions involve complex social aggregation processes (Felin et al., 2015; Smith \& Rand, 2017).

Finally, it is worth repeating that empirical findings from experimental research, like those reported here, are generalizable only via theory rather than through one-to-one application (Kanazawa, 1999; Lucas, 2003b; Martin \& Sell, 1979; Zelditch, 1980). Clearly, simplifying assumptions and a focus on the features of particular theoretical interest are necessary to bring organizational research questions into the laboratory, trading off enhanced internal validity for a certain degree of external validity. Therefore, experimental studies in institutional theory should spark further research that uses complementary methods (Levine, 2003), most notably qualitative work (Zilber, 2016), to shed more light on the dynamic process by which organizational identity develops and is negotiated in organizations. Such studies will also be able to scrutinize the extent to which the findings reported here generalize to populations of practicing managers in large corporations outside the laboratory. As such, the current investigation provides plenty of opportunity for future research (e.g., lab studies involving practitioners, field replications, mixed methods work) to further validate the findings reported here. Nonetheless, it is important to note that the usage of realistic and plausible scenarios, such as in this study, can help to reduce concerns about experiments' external validity (Finch, 1987). As institutions are otherwise difficult to research in real time, the use of scenario techniques allows for "introducing" environmental pressures while assessing the effect of focal independent variables in situ and not in a vacuum.

Overall, it is clear that microinstitutionalism is still in its infancy and that most of the work in this field lies ahead (Powell \& Colyvas, 2008; Zucker, 1991). My research adds to this emerging research stream by building a strong argument for microinstitutionalism that goes beyond exploring micro links for their own sake and instead showing how the development of microfoundations can further our understanding of organizational theory addressing organizational practice adoption and deviance. Extending the current investigation, future research is needed to develop a more comprehensive understanding of the various conditions and mechanisms relevant to decision-makers conforming with versus resisting environmental pressures. Moreover, environmental pressures often contradict each other in reality, making it important to study how decisionmakers process and prioritize competing institutional logics (Glaser et al., 2016). It is also clear that responses to institutional pressures do not always follow a binary conformance-versus-resistance choice; thus, qualitatively different types of responses should be investigated as well (Oliver, 1991; Yoo, Bachmann, \& Schilke, 2016), most notably strategies that are at the heart of the institutional work literature, such as challenging, attacking, and manipulating institutions (Lawrence, Leca, \& Zilber, 
2013). Another significant limitation in extant work is that institutionalization has rarely been studied as a dynamic process, so our current understanding of the individual stages through which institutionalization occurs is at best incomplete (Schilke \& Cook, 2013; Tolbert \& Zucker, 1996). Finally, a comprehensive approach to microinstitutionalism will need to expand its focus to analyze not only decisionmakers in organizations but members of external audiences as well. Only rarely have institutionalists explicitly studied the antecedents and cognitive consequences of audiences' legitimacy judgments (Haack et al., 2016), despite the centrality of this concept in institutional theory (Tost, 2011). In sum, I expect microinstitutionalism to provide a particularly fertile ground for inquiry in the years to come.

\section{CONCLUSIONS}

In conclusion, this research provides valuable novel findings on a key source of resistance to environmental pressures. It goes significantly beyond the traditional neo-institutional macro-level approach to delve into cognitive processes that help to explain organizational choices. The organizational actor and his/her relationships to the organization and its environment assume center stage in this line of inquiry that the current investigation aims to bolster, thus laying further groundwork for a micro-institutional agenda of research aimed at opening the black box of organizational decision-making.

\section{REFERENCES}

Abrams, D., \& Hogg, M. A. 1990. Social identification, selfcategorization and social influence. European Review of Social Psychology, 1: 195-228.

Albert, S., \& Whetten, D. A. 1985. Organizational identity. Research in Organizational Behavior, 7: 263-295.

Aldrich, H. E., \& Rueff, M. 2006. Organizations evolving. Thousand Oaks, CA: SAGE.

Ashforth, B. E., Harrison, S. H., \& Corley, K. G. 2008. Identification in organizations: An examination of four fundamental questions. Journal of Management, 34: $325-374$.

Ashforth, B. E., \& Mael, F. 1989. Social identity theory and the organization. Academy of Management Review, 14: 20-39.

Ashforth, B. E., Rogers, K. M., \& Corley, K. G. 2011. Identity in organizations: Exploring cross-level dynamics. Organization Science, 22: 1144-1156.

Barley, S. R. 2008. Coalface institutionalism. In R. Greenwood, C. Oliver, K. Sahlin \& R. Suddaby
(Eds.), The SAGE handbook of organizational institutionalism: 491-518. London, England: SAGE.

Baron, R. M., \& Kenny, D. A. 1986. The moderatormediator variable distinction in social psychological research: Conceptual, strategic, and statistical considerations. Journal of Personality and Social Psychology, 51: 1173-1182.

Barreto, I., \& Baden-Fuller, C. 2006. To conform or to perform? Mimetic behaviour, legitimacy-based groups and performance consequences. Journal of Management Studies, 43: 1559-1581.

Battilana, J. 2006. Agency and institutions: The enabling role of individuals' social position. Organization, 13: 653-676.

Battilana, J., \& D’Aunno, T. 2009. Institutional work and the paradox of embedded agency. In T. Lawrence, R. Suddaby \& B. Leca (Eds.), Institutional work: Actors and agency in institutional studies of organizations: 31-58. Cambridge, England: Cambridge University Press.

Battilana, J., \& Dorado, S. 2010. Building sustainable hybrid organizations: The case of commercial microfinance organizations. Academy of Management Journal, 53: 1419-1440.

Battilana, J., Leca, B., \& Boxenbaum, E. 2009. How actors change institutions: Towards a theory of institutional entrepreneurship. The Academy of Management Annals, 3: 65-107.

Bechky, B. A. 2011. Making organizational theory work: Institutions, occupations, and negotiated orders. Organization Science, 22: 1157-1167.

Bergami, M., \& Bagozzi, R. P. 2000. Self-categorization, affective commitment and group self-esteem as distinct aspects of social identity in the organization. British Journal of Social Psychology, 39: 555-577.

Berger, J. 2007. The standardized experimental situation in expectation states research: Notes on history, uses, and special features. In M. Webster \& J. Sell (Eds.), Laboratory experiments in the social sciences: 353-378. Amsterdam, Netherlands: Academic Press.

Berger, J., \& Fisek, M. H. 1970. Consistent and inconsistent status characteristics and the determination of power and prestige orders. Sociometry, 33: 287-304.

Berger, P. L., \& Luckmann, T. 1966. The social construction of reality: A treatise in the sociology of knowledge. Garden City, NY: Doubleday.

Berinsky, A. J., Margolis, M. F., \& Sances, M. W. 2014. Separating the shirkers from the workers? Making sure respondents pay attention on self-administered surveys. American Journal of Political Science, 58: 739-753.

Berrone, P., Fosfuri, A., Gelabert, L., \& Gomez-Mejia, L. R. 2013. Necessity as the mother of "green" inventions: 
Institutional pressures and environmental innovations. Strategic Management Journal, 34: 891-909.

Besharov, M. L., \& Brickson, S. L. 2016. Organizational identity and institutional forces: Toward an integrative framework. In M. Pratt, M. Schultz, B. Ashforth \& D. Ravasi (Eds.), The Oxford handbook of organizational identity: 396-416. Oxford, England: Oxford University Press.

Binder, A. 2007. For love and money: Organizations' creative responses to multiple environmental logics. Theory and Society, 36: 547-571.

Bitektine, A. 2009. What makes us faddish? Resource space constraints and the "garbage can" model of social science research. Scandinavian Journal of Management, 25: 217-220.

Bitektine, A. 2011. Toward a theory of social judgments of organizations: The case of legitimacy, reputation, and status. Academy of Management Review, 36: 151-179.

Bitektine, A., \& Haack, P. 2015. The "macro" and the "micro" of legitimacy: Toward a multilevel theory of the legitimacy process. Academy of Management Review, 40: 49-75.

Bitektine, A., Lucas, J., \& Schilke, O. 2018. Institutions under a microscope: Experimental methods in institutional theory. In A. Bryman \& D. A. Buchanan (Eds.), Unconventional methodology in organization and management research: 147-167. Oxford, England: Oxford University Press.

Bitektine, A., \& Miller, D. 2015. Methods, theories, data, and the social dynamics of organizational research. Journal of Management Inquiry, 24: 115-130.

Boxenbaum, E. 2014. Toward a situated stance in organizational institutionalism: Contributions from French pragmatist sociology theory. Journal of Management Inquiry, 23: 319-323.

Brewer, M. B. 1979. In-group bias in the minimal intergroup situation: A cognitive-motivational analysis. Psychological Bulletin, 86: 307-324.

Brewer, M. B. 1985. Experimental research and social policy: Must it be rigor versus relevance? The Journal of Social Issues, 41: 159-176.

Brown, A. D., Humphreys, M., \& Gurney, P. M. 2005. Narrative, identity and change: A case study of Laskarina Holidays. Journal of Organizational Change Management, 18: 312-326.

Buhrmester, M., Kwang, T., \& Gosling, S. D. 2011. Amazon’s Mechanical Turk: A new source of inexpensive, yet high-quality, data? Perspectives on Psychological Science, 6: 3-5.

Cadinu, M. R., \& Rothbart, M. 1996. Self-anchoring and differentiation processes in the minimal group setting. Journal of Personality and Social Psychology, 70: 661-677.
Chandler, D., \& Hwang, H. 2015. Learning from learning theory: A model of organizational adoption strategies at the microfoundations of institutional theory. Journal of Management, 41: 1446-1476.

Creed, D. W. E., Hudson, B. A., Okhuysen, G. A., \& SmithCrowe, K. 2014. Swimming in a sea of shame: Incorporating emotion into explanations of institutional reproduction and change. Academy of Management Review, 39: 275-301.

David, R. J., \& Bitektine, A. B. 2009. The deinstitutionalization of institutional theory? Exploring divergent agendas in institutional research. In A. Bryman \& D. Buchanan (Eds.), The SAGE handbook of organizational research methods: 160-175. London, England: SAGE.

Dejordy, R., \& Creed, W. E. D. 2016. Institutional pluralism, inhabitants, and the construction of organizational and personal identities. In M. Pratt, M. Schultz, B. Ashforth \& D. Ravasi (Eds.), The Oxford handbook of organizational identity: 374-395. Oxford, England: Oxford University Press.

Dhalla, R., \& Oliver, C. 2013. Industry identity in an oligopolistic market and firms' responses to institutional pressures. Organization Studies, 34: 1803-1834.

DiMaggio, P. 1988. Interest and agency in institutional theory. In L. G. Zucker (Ed.), Institutional patterns and organizations: Culture and environment: 3-21. Cambridge, MA: Ballinger.

DiMaggio, P., \& Markus, H. R. 2010. Culture and social psychology: Converging perspectives. Social Psychology Quarterly, 73: 347-352.

DiMaggio, P., \& Powell, W. W. 1983. The iron cage revisited: Institutional isomorphism and collective rationality in organizational fields. American Sociological Review, 48: 147-160.

DiMaggio, P., \& Powell, W. W. 1991. Introduction. In W. W. Powell \& P. DiMaggio (Eds.), The new institutionalism in organization analysis: $1-38$. Chicago, IL: University of Chicago Press.

Doosje, B., Spears, R., \& Koomen, W. 1995. When bad isn't all bad: Strategic use of sample information in generalization and stereotyping. Journal of Personality and Social Psychology, 69: 642-655.

Dutton, J. E. 1986. Understanding strategic agenda building and its implications for managing change. Scandinavian Journal of Management Studies, 3: 3-24.

Dutton, J. E., \& Dukerich, J. M. 1991. Keeping an eye on the mirror: Image and identity in organizational adaptation. Academy of Management Journal, 34: 517-554.

Dutton, J. E., \& Penner, W. J. 1993. The importance of organizational identity for strategic agenda building. In J. Hendry \& G. Johnson (Eds.), Strategic thinking: 
Leadership and the management of change: 89-113. Chichester, England: Wiley.

Ellemers, N., Spears, R., \& Doosje, B. 1997. Sticking together or falling apart: In-group identification as a psychological determinant of group commitment versus individual mobility. Journal of Personality and Social Psychology, 72: 617-626.

Ellemers, N., Spears, R., \& Doosje, B. 2002. Self and social identity. Annual Review of Psychology, 53: 161-186.

Etzioni, A. 1961. A comparative analysis of complex organizations. New York, NY: Free Press.

Fan, G. H., \& Zietsma, C. 2017. Constructing a shared governance logic: The role of emotions in enabling dually embedded agency. Academy of Management Journal, 60: 2321-2351.

Felin, T., Foss, N. J., \& Ployhart, R. E. 2015. The microfoundations movement in strategy and organization theory. The Academy of Management Annals, 9: 575-632.

Finch, J. 1987. The vignette technique in survey research. Sociology, 21: 105-114.

Fine, G. A., \& Hallett, T. 2014. Group cultures and the everyday life of organizations: Interaction orders and meso-analysis. Organization Studies, 35: 1773-1792.

Fiol, C. M., \& O’Connor, E. J. 2003. Waking up! Mindfulness in the face of bandwagons. Academy of Management Review, 28: 54-70.

Foreman, P., \& Whetten, D. A. 2002. Members' identification with multiple-identity organizations. Organization Science, 13: 618-635.

Foschi, M. 1996. Double standards in the evaluation of men and women. Social Psychology Quarterly, 59: 237254.

Fox-Wolfgramm, S. J., Boal, K. B., \& Hunt, J. G. 1998. Organizational adaptation to institutional change: A comparative study of first-order change in prospector and defender banks. Administrative Science Quarterly, 43: 87-126.

Fransen, K., Haslam, S. A., Steffens, N. K., Vanbeselaere, N., De Cuyper, B., \& Boen, F. 2015. Believing in "us": Exploring leaders' capacity to enhance team confidence and performance by building a sense of shared social identity. Journal of Experimental Psychology: Applied, 21: 89-100.

Gavetti, G., Levinthal, D., \& Ocasio, W. 2007. Neo-Carnegie: The Carnegie School's past, present, and reconstructing for the future. Organization Science, 18: 523-536.

George, E., \& Chattopadhyay, P. 2005. One foot in each camp: The dual identification of contract workers. Administrative Science Quarterly, 50: 68-99.

George, E., Chattopadhyay, P., Sitkin, S. B., \& Barden, J. 2006. Cognitive underpinnings of institutional persistence and change: A framing perspective. Academy of Management Review, 31: 347-365.

Gioia, D. A., Patvardhan, S. D., Hamilton, A. L., \& Corley, K. G. 2013. Organizational identity formation and change. The Academy of Management Annals, 7: 123-193.

Gioia, D. A., Price, K. N., Hamilton, A. L., \& Thomas, J. B. 2010. Forging an identity: An insider-outsider study of processes involved in the formation of organizational identity. Administrative Science Quarterly, 55: $1-46$.

Gioia, D. A., Schultz, M., \& Corley, K. G. 2000. Organizational identity, image, and adaptive instability. Academy of Management Review, 25: 63-81.

Gioia, D. A., \& Thomas, J. B. 1996. Identity, image, and issue interpretation: Sensemaking during strategic change in academia. Administrative Science Quarterly, 41: 370-403.

Glaser, V. L., Fast, N. J., Harmon, D. J., \& Green, S. 2016. Institutional frame switching: How institutional logics shape individual action. Research in the Sociology of Organizations, 48A: 35-69.

Glaser, V., Kroezen, J., \& Thornton, P. H. 2015. Learning institutional logics. Paper presented at the Fourth Triennial Alberta Institutions Conference, Banff, Alberta, Canada.

Glynn, M. A. 2000. When cymbals become symbols: Conflict over organizational identity within a symphony orchestra. Organization Science, 11: 285-298.

Glynn, M. A. 2008. Beyond constraint: How institutions enable identities. In R. Greenwood, C. Oliver, K. Sahlin \& R. Suddaby (Eds.), The SAGE handbook of organizational institutionalism: 413-430. Thousand Oaks, CA: SAGE.

Greenwood, R., Hinings, C. R., \& Whetten, D. 2014. Rethinking institutions and organizations. Journal of Management Studies, 51: 1206-1220.

Greenwood, R., Raynard, M., Kodeih, F., Micelotta, E. R., \& Lounsbury, M. 2011. Institutional complexity and organizational responses. The Academy of Management Annals, 5: 317-371.

Greenwood, R., Suddaby, R., \& Hinings, C. R. 2002. Theorizing change: The role of professional associations in the transformation of institutionalized fields. Academy of Management Journal, 45: 58-80.

Grieve, P. G., \& Hogg, M. A. 1999. Subjective uncertainty and intergroup discrimination in the minimal group situation. Personality and Social Psychology Bulletin, 25: 926-940.

Haack, P., McKinley, W., Schilke, O., \& Zucker, L. G. 2016. The theory-method gap in organizational legitimacy research: A critical review, synthesis, and directions for future research. Paper presented at the American 
Sociological Association Annual Meeting, Seattle, WA.

Hafenbrädl, S., \& Waeger, D. 2017. Ideology and the microfoundations of CSR: Why executives believe in the business case for CSR and how this affects their CSR engagements. Academy of Management Journal, 27: 502-520.

Hallett, T. 2010a. From inhabited institutions to an inhabited institutionalism? Exploring the theoretical position of inhabited institutionalism. Paper presented at the 2010 EGOS Colloquium: Microfoundations of Institutions, Lisbon, Portugal.

Hallett, T. 2010b. The myth incarnate: Recoupling processes, turmoil, and inhabited institutions in an urban elementary school. American Sociological Review, 75: 52-74.

Hallett, T., \& Ventresca, M. J. 2006. Inhabited institutions: Social interactions and organizational forms in Gouldner's patterns of industrial bureaucracy. Theory and Society, 35: 213-236.

Hambrick, D. C., \& Mason, P. A. 1984. Upper echelons: The organization as a reflection of its top managers. Academy of Management Review, 9: 193-206.

Harquail, C. V. 2006. Making use of organizational identity: Icons as symbolic identity proxies (Working paper). Stockholm, Sweden: Stockholm School of Economics.

Haslam, S. A. 2004. Psychology in organizations: The social identity approach (2nd ed.). Thousand Oaks, CA: SAGE.

Haslam, S. A., Postmes, T., \& Ellemers, N. 2003. More than a metaphor: Organizational identity makes organizational life possible. British Journal of Management, 14: 357-369.

Hatch, M. J., \& Zilber, T. 2012. Conversation at the border between organizational culture theory and institutional theory. Journal of Management Inquiry, 21: 94-97.

Hayes, A. F. 2013. Introduction to mediation, moderation, and conditional process analysis: A regressionbased approach. New York, NY: Guilford Press.

Hayes, A. F., \& Preacher, K. J. 2014. Statistical mediation analysis with a multicategorical independent variable. British Journal of Mathematical \& Statistical Psychology, 67: 451-470.

Heath, C., \& Sitkin, S. B. 2001. Big-B versus Big-O: What is organizational about organizational behavior? Journal of Organizational Behavior, 22: 43-58.

Helms, W. S., Oliver, C., \& Webb, K. 2012. Antecedents of settlement on a new institutional practice: Negotiation of the ISO 26000 standard on social responsibility. Academy of Management Journal, 55: 1120-1145.
Heugens, P. P. M. A. R., \& Lander, M. W. 2009. Structure! Agency! (And other quarrels): A meta-analysis of institutional theories of organization. Academy of Management Journal, 52: 61-85.

Higgins, E. T. 1996. Knowledge activation: Accessibility, applicability, and salience. In E. T. Higgins \& A. W. Kruglanski (Eds.), Social psychology: Handbook of basic principles: 133-168. New York, NY: Guilford Press.

Hogg, M. A. 2000. Subjective uncertainty reduction through self-categorization: A motivational theory of social identity processes. European Review of Social Psychology, 11: 223-255.

Hogg, M. A. 2007. Uncertainty-identity theory. Advances in Experimental Social Psychology, 39: 69-126.

Hogg, M. A., \& Terry, D. J. 2000. Social identity and selfcategorization processes in organizational contexts. Academy of Management Review, 25: $121-140$

Hwang, H., \& Colyvas, J. A. 2011. Problematizing actors and institutions in institutional work. Journal of Management Inquiry, 20: 62-66.

Kanazawa, S. 1999. Using laboratory experiments to test theories of corporate behavior. Rationality and Society, 11: 443-461.

Kennedy, M. T., \& Fiss, P. C. 2009. Institutionalization, framing, and diffusion: The logic of TQM adoption and implementation decisions among U.S. hospitals. Academy of Management Journal, 52: 897-918.

King, B. G., Felin, T., \& Whetten, D. A. 2010. Finding the organization in organizational theory: A meta-theory of the organization as a social actor. Organization Science, 21: 290-305.

Kraatz, M. S., \& Block, E. S. 2008. Organizational implications of institutional pluralism. In R. Greenwood, C. Oliver, K. Sahlin \& R. Suddaby (Eds.), The SAGE handbook of organizational institutionalism: 243275. Thousand Oaks, CA: SAGE.

Kraatz, M. S., \& Zajac, E. J. 1996. Exploring the limits of the new institutionalism: The causes and consequences of illegitimate organizational change. American Sociological Review, 61: 812-836.

Kroezen, J. J., \& Heugens, P. P. M. A. R. 2012. Organizational identity formation: Processes of identity imprinting and enactment in the Dutch microbrewing landscape. In M. Schultz, S. Maguire, A. Langley \& H. Tsoukas (Eds.), Constructing identity in and around organizations, vol. 2: 89-127. Oxford, England: Oxford University Press.

Lamertz, K., Heugens, P. P. M. A. R., \& Calmet, L. 2005. The configuration of organizational images among firms in the Canadian beer brewing industry. Journal of Management Studies, 42: 817-843. 
Lant, T. K., \& Montgomery, D. B. 1992. Simulation games as a research method for studying strategic decisionmaking: The case of MARKSTRAT (Working paper). Stanford, CA: Stanford University.

Lawrence, T. B., Leca, B., \& Zilber, T. B. 2013. Institutional work: Current research, new directions and overlooked issues. Organization Studies, 34: 1023-1033.

Lawrence, T., Suddaby, R., \& Leca, B. 2011. Institutional work: Refocusing institutional studies of organization. Journal of Management Inquiry, 20: 52-58.

Leuthesser, L., \& Kohli, C. 1997. Corporate identity: The role of mission statements. Business Horizons, 40: 59-66.

Levine, M. 2003. Times, theories and practices in social psychology. Theory \& Psychology, 13: 53-72.

Levine, S. S., Apfelbaum, E. P., Bernard, M., Bartelt, V. L., Zajac, E. J., \& Stark, D. 2014. Ethnic diversity deflates price bubbles. Proceedings of the National Academy of Sciences of the United States of America, 111: 18524-18529.

Levine, S. S., \& Zajac, E. J. 2008. Institutionalization in efficient markets: The case of price bubbles. Academy of Management Best Paper Proceedings, 2008: 1-6.

Leyens, J.-P., Yzerbyt, V. Y. A., \& Schadron, G. 1994. Stereotypes and social cognition. London, England: SAGE.

Lucas, J. W. 2003a. Status processes and the institutionalization of women as leaders. American Sociological Review, 68: 464-480.

Lucas, J. W. 2003b. Theory testing, generalization, and the problem of external validity. Sociological Theory, 21: 236-253.

Mackie, D. M., Gastardo-Conaco, M. C., \& Skelly, J. J. 1992. Knowledge of the advocated position and the processing of in-group and out-group persuasive messages. Personality and Social Psychology Bulletin, 18: 145-151.

Mackie, D. M., Worth, L. T., \& Asuncion, A. G. 1990. Processing of persuasive in-group messages. Journal of Personality and Social Psychology, 58: 812-822.

Martin, M. W., \& Sell, J. 1979. The role of the experiment in the social sciences. The Sociological Quarterly, 20: 581-590.

Meyer, J. W., \& Rowan, B. 1977. Institutionalized organizations: Formal structure as myth and ceremony. American Journal of Sociology, 83: 340-363.

Mizruchi, M. S., \& Fein, L. C. 1999. The social construction of organizational knowledge: A study of the uses of coercive, mimetic, and normative isomorphism. Administrative Science Quarterly, 44: 653-683.

Molm, L. D. 2007. Experiments on exchange relations and exchange networks in sociology. In M. Webster \& J. Sell (Eds.), Laboratory experiments in the social sciences: 379-406. Amsterdam, Netherlands: Academic Press.

Moss, T. W., Short, J. C., Payne, G. T., \& Lumpkin, G. T. 2011. Dual identities in social ventures: An exploratory study. Entrepreneurship Theory and Practice, 35: 805-830.

Mullin, B.-A., \& Hogg, M. A. 1998. Dimensions of subjective uncertainty in social identification and minimal intergroup discrimination. British Journal of Social Psychology, 37: 345-365.

Nigam, A., \& Ocasio, W. 2010. Event attention, environmental sensemaking, and change in institutional logics: An inductive analysis of the effects of public attention to Clinton's health care reform initiative. Organization Science, 21: 823-841.

Ocasio, W. 2011. Attention to attention. Organization Science, 22: 1286-1296.

Okhuysen, G., \& Bonardi, J.-P. 2011. The challenges of building theory by combining lenses. Academy of Management Review, 36: 6-11.

Oliver, C. 1991. Strategic responses to institutional processes. Academy of Management Review, 16: 145-179.

Oliver, C. 1992. The antecedents of deinstitutionalization. Organization Studies, 13: 563-588.

Otten, S., \& Epstude, K. 2006. Overlapping mental representations of self, ingroup, and outgroup: Unraveling self-stereotyping and self-anchoring. Personality and Social Psychology Bulletin, 32: 957-969.

Pache, A.-C., \& Santos, F. 2010. When worlds collide: The internal dynamics of organizational responses to conflicting institutional demands. Academy of Management Review, 35: 455-476.

Pache, A.-C., \& Santos, F. 2013. Embedded in hybrid contexts: How individuals in organizations respond to competing institutional logics. Research in the Sociology of Organizations, 39(B): 3-35.

Park, S., Sine, W. D., \& Tolbert, P. S. 2011. Professions, organizations, and institutions: Tenure systems in colleges and universities. Work and Occupations, 38: 340-371.

Parsons, T. 1960. Structure and process in modern societies. New York, NY: Free Press.

Pearce, J. A., \& David, F. 1987. Corporate mission statements: The bottom line. The Academy of Management Executive, 1: 109-115.

Pedersen, J. S., \& Dobbin, F. 2006. In search of identity and legitimation: Bridging organizational culture and neoinstitutionalism. The American Behavioral Scientist, 49: 897-907.

Powell, W. W. 1991. Expanding the scope of institutional analysis. In W. W. Powell \& P. J. DiMaggio (Eds.), The new institutionalism in organizational analysis: 183-203. Chicago, IL: University of Chicago Press. 
Powell, W. W., \& Bromley, P. 2015. New institutionalism in the analysis of complex organizations. In J. D. Wright (Ed.), International encyclopedia of social and behavioral sciences, vol. 16 (2nd ed.): 764-769. Oxford, England: Elsevier.

Powell, W. W., \& Colyvas, J. A. 2008. Microfoundations of institutional theory. In R. Greenwood, C. Oliver, K. Sahlin \& R. Suddaby (Eds.), The SAGE handbook of organizational institutionalism: 276-298. Thousand Oaks, CA: SAGE.

Preacher, K. J., \& Hayes, A. F. 2004. SPSS and SAS procedures for estimating indirect effects in simple mediation models. Behavior Research Methods, Instruments, \& Computers, 36: 717-731.

Preacher, K. J., \& Kelley, K. 2011. Effect size measures for mediation models: Quantitative strategies for communicating indirect effects. Psychological Methods, 16: 93-115.

Prinzmetal, W., McCool, C., \& Park, S. 2005. Attention: Reaction time and accuracy reveal different mechanisms. Journal of Experimental Psychology: General, 134: 73-92.

Raaijmakers, A., Vermeulen, P., Meeus, M., \& Zietsma, C. 2015. I need time! Exploring pathways to compliance under institutional complexity. Academy of Management Journal, 58: 85-110.

Rabe-Hesketh, S., \& Skrondal, A. 2012. Multilevel and longitudinal modeling using Stata (3rd ed.). College Station, TX: Stata Press Publication.

Raffaelli, R., \& Glynn, M. A. 2014. Turnkey or tailored? Relational pluralism, institutional complexity, and the organizational adoption of more or less customized practices. Academy of Management Journal, 57: 541-562.

Ridgeway, C. L. 2006. Linking social structure and interpersonal behavior: A theoretical perspective on cultural schemas and social relations. Social Psychology Quarterly, 69: 5-16.

Rossman, G., \& Schilke, O. 2014. Close, but no cigar: The bimodal rewards to prize-seeking. American Sociological Review, 79: 86-108.

Schilke, O., \& Cook, K. S. 2013. A cross-level process theory of trust development in interorganizational relationships. Strategic Organization, 11: 281-303.

Schreyögg, G., \& Sydow, J. 2011. Organizational path dependence: A process view. Organization Studies, 32: 321-335.

Scott, W. R. 2014. Institutions and organizations: Ideas, interests, and identities (4th ed.). Los Angeles, CA: SAGE.

Selznick, P. 1957. Leadership in administration: A sociological interpretation. Evanston, IL: Row.
Sherif, M., Harvey, O. J., White, B. J., Hood, W. R., \& Sherif, C. W. 1961. Intergroup conflict and cooperation: The Robbers Cave experiment. Norman, OK: University Book Exchange.

Sluss, D. M., \& Ashforth, B. E. 2007. Relational identity and identification: Defining ourselves through work relationships. Academy of Management Review, 32: 9-32.

Smith, E. B., \& Rand, W. 2017. Simulating macro-level effects from micro-level observations. Management Science. Published online ahead of print. doi: 10.1287/ mnsc.2017.2877

Sniezek, J. A. 1992. Groups under uncertainty: An examination of confidence in group decision-making. Organizational Behavior and Human Decision Processes, 52: 124-155.

Stapel, D. A., Reicher, S. D., \& Spears, R. 1994. Social identity, availability and the perception of risk. Social Cognition, 12: 1-17.

Staw, B. M. 1976. Knee-deep in the big muddy: A study of escalating commitment to a chosen course of action. Organizational Behavior and Human Performance, 16: 27-44.

Steele, C. W., \& King, B. G. 2011. Collective intentionality in organizations: A meta-ethnography of identity and strategizing. Advances in Group Processes, 28: 5995.

Stinchcombe, A. L. 1991. The conditions of fruitfulness of theorizing about mechanisms in social science. Philosophy of the Social Sciences, 21: 367-388.

Stolte, J. F., Fine, G. A., \& Cook, K. S. 2001. Sociological miniaturism: Seeing the big through the small in social psychology. Annual Review of Sociology, 27: 387-413.

Sturdy, A. 2004. The adoption of management ideas and practices: Theoretical perspectives and possibilities. Management Learning, 35: 155-179.

Suddaby, R. 2010. Challenges for institutional theory. Journal of Management Inquiry, 19: 14-20.

Suddaby, R., Elsbach, K. D., Greenwood, R., Meyer, J. W., \& Zilber, T. B. 2010. Organizations and their institutional environments: Bringing meaning, values, and culture back in. Academy of Management Journal, 53: 1234-1240.

Suddaby, R., Viale, T., \& Gendron, Y. 2016. Reflexivity: The role of embedded social position and entrepreneurial social skill in processes of field level change. Research in Organizational Behavior, 36: 225-245.

Tajfel, H., Billig, M. G., Bundy, R. P., \& Flament, C. 1971. Social categorization and intergroup behaviour. European Journal of Social Psychology, 1: 149-178.

Thau, S., Pitesa, M., \& Pillutla, M. 2014. Experiments in organizational behavior. In M. Webster \& J. Sell (Eds.), Laboratory experiments in the social sciences: 433-447. San Diego, CA: Academic Press. 
Thornton, P. H., \& Ocasio, W. 1999. Institutional logics and the historical contingency of power in organizations: Executive succession in the higher education publishing industry, 1958-1990. American Journal of Sociology, 105: 801-843.

Thornton, P. H., \& Ocasio, W. 2008. Institutional logics. In R. Greenwood, C. Oliver, K. Sahlin \& R. Suddaby (Eds.), The SAGE handbook of organizational institutionalism: 99-129. Los Angeles, CA: SAGE.

Thornton, P. H., Ocasio, W., \& Lounsbury, M. 2012. The institutional logics perspective: A new approach to culture, structure and process. Oxford, England: Oxford University Press.

Tolbert, P. S., David, R. J., \& Sine, W. D. 2011. Studying choice and change: The intersection of institutional theory and entrepreneurship research. Organization Science, 22: 1332-1344.

Tolbert, P. S., \& Zucker, L. G. 1996. The institutionalization of institutional theory. In S. Clegg, C. Hardy \& W. R. Nord (Eds.), Handbook of organization studies: 175-190. London, England: SAGE.

Tost, L. P. 2011. An integrative model of legitimacy judgments. Academy of Management Review, 36: 686-710.

Turner, J. C. 1982. Towards a cognitive redefinition of the social group. In H. Tajfel (Ed.), Social identity and intergroup relations: 15-40. Cambridge, England: Cambridge University Press.

Turner, J. C. 1987. Rediscovering the social group: Selfcategorization theory. Oxford, England: Blackwell.

Turner, J. C., Hogg, M. A., Turner, P. J., \& Smith, P. M. 1984. Failure and defeat as determinants of group cohesiveness. British Journal of Social Psychology, 23: 97-111.

Wason, K. D., Polonsky, M. J., \& Hyman, M. R. 2002. Designing vignette studies in marketing. Australasian Marketing Journal, 10: 41-58.

Weber, K., \& Glynn, M. A. 2006. Making sense with institutions: Context, thought and action in Karl Weick's theory. Organization Studies, 27: 1639-1660.

Webster, M., \& Sell, J. 2007. Why do experiments? In M. Webster \& J. Sell (Eds.), Laboratory experiments in the social sciences: 5-23. Amsterdam, Netherlands: Academic Press.

Weinberg, J. D., Freese, J., \& McElhattan, D. 2014. Comparing data characteristics and results of an online factorial survey between a population-based and a crowdsource-recruited sample. Sociological Science, 1: 292-310.

Whetten, D. A. 2006. Albert and Whetten revisited: Strengthening the concept of organizational identity. Journal of Management Inquiry, 15: 219-234.

Whetten, D. A., \& Mackey, A. 2002. A social actor conception of organizational identity and its implications for the study of organizational reputation. Business $\mathcal{E}$ Society, 41: 393-414.

Yoo, T., Bachmann, R., \& Schilke, O. 2016. Acquiescent defiance: Tuscan wineries' partial reactivity to the Italian government's quality regulation system. Paper presented at the Annual Meeting of the Academy of Management, Anaheim, CA.

Zelditch, M. 1980. Can you really study an army in a laboratory? In A. Etzioni \& E. W. Lehman (Eds.), A sociological reader on complex organizations (3rd ed.): 528-539. New York, NY: Holt, Rinehart, and Winston.

Zhao, X., Lynch, J., \& Chen, Q. 2010. Reconsidering Baron and Kenny: Myths and truths about mediation analysis. The Journal of Consumer Research, 37: 197-206.

Zilber, T. B. 2002. Institutionalization as an interplay between actions, meanings, and actors: The case of a rape crisis center in Israel. Academy of Management Journal, 45: 234-254.

Zilber, T. B. 2008. The work of meanings in institutional processes. In R. Greenwood, C. Oliver, K. Sahlin \& R. Suddaby (Eds.), The SAGE handbook of organizational institutionalism: 151-169. London, England: SAGE.

Zilber, T. B. 2016. How institutional logics matter: A bottom-up exploration. Research in the Sociology of Organizations, 48A: 137-155.

Zucker, L. G. 1977. The role of institutionalization in cultural persistence. American Sociological Review, 42: 726-743.

Zucker, L. G. 1983. Organizations as institutions. Research in the Sociology of Organizations, 2: 1-47.

Zucker, L. G. 1987. Institutional theories of organization. Annual Review of Sociology, 13: 443-464.

Zucker, L. G. 1991. Postscript: Microfoundations of institutional thought. In W. W. Powell \& P. DiMaggio (Eds.), The new institutionalism in organizational analysis: 103-106. Chicago, IL: University of Chicago Press.

Zucker, L. G., \& Darby, M. R. 2005. An evolutionary approach to institutions and social construction: Process and structure. In K. G. Smith \& M. A. Hitt (Eds.), Great minds in management: The process of theory development: 547-571. Oxford, England: Oxford University Press.

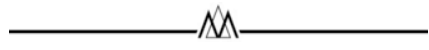

Oliver Schilke (oschilke@arizona.edu) is an assistant professor of management and organizations (tenure track) and an assistant professor of sociology (by courtesy) at the University of Arizona. He received his PhD from UCLA. Oliver is primarily interested in organizational theory, and much of his extant research has examined issues related to 
routines and trust, often in the context of interorganizational relationships and applying an institutional theory lens. His current research contributes to elaborating the microfoundations of institutional theory.

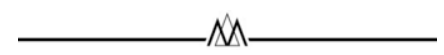

\section{APPENDIX A}

\section{Study 1, Main Task-Organizational Problems Used}

Initially, I created a long list of 30 decision scenarios (each consisting of a question and two answer choices) based on a variety of strategy and marketing textbooks and case studies. I then ran a pretest via MTurk $(n=41)$, in which I asked participants to select a response and then indicate how certain they were about their choice (on a scale from 1 to 7 ) for each of the 30 questions. Focusing on those questions with relatively little behavioral response variance and high levels of perceived certainty, I dropped five questions and slightly reworded others to make sure that questions were sufficiently ambiguous and certain answer choices didn't appear objectively superior. The full list of the 25 organizational problems used in Study 1 appears below. The self-reported mean of perceived certainty across these 25 questions in the MTurk pretest was $4.61(S D=0.35)$.

(1) Your group's flower shop needs to reduce personnel costs. Which of the following solutions do you choose?

- Discharge a small number of employees

- Reduce the working hours of all employees

(2) Your group's flower shop needs to decide on its hiring policy. Which of the following solutions do you choose?

- Hire certified florists only

- Hire motivated people no matter their education

(3) Your group's flower shop needs to decide on its geographic scope. Which of the following solutions do you choose?

- Focus on local area

- Spread over various regions

(4) Your group's flower shop needs to decide on its product breadth. Which of the following solutions do you choose?

- Focus on flowers only

- Offer flowers and other garden products

(5) Your group's flower shop needs to decide on its pricing strategy. Which of the following solutions do you choose?

- Low prices (meaning low profit margins but higher volumes)
- High prices (meaning high profit margins but lower volumes)

(6) Your group's flower shop needs to decide on its replenishment system. Which of the following solutions do you choose?

- Reordering inventory at fixed points in time

- Reordering inventory when running low

(7) Your group's flower shop needs to decide on price variations. Which of the following solutions do you choose?

- Keep prices constant throughout the year (to reduce consumer confusion)

- Run frequent price promotions

(8) Your group's flower shop needs to decide on its flower portfolio. Which of the following solutions do you choose?

- Wide variety of flowers from all over the world

- Specific types of flowers the shop is known for

(9) Your group's flower shop needs to decide on the location for a new branch. Which of the following solutions do you choose?

- Open branch in a shopping mall

- Open branch downtown

(10) Your group's flower shop needs to decide on who places orders. Which of the following solutions do you choose?

- Orders are placed centrally by corporate management

- Orders are placed decentrally by every branch manager

(11) Your group's flower shop needs to decide on its ownership form. Which of the following solutions do you choose?

- Privately held company

- Publicly traded company

(12) Your group's flower shop needs to decide on the target segment of its next ad campaign. Which of the following solutions do you choose?

- Weddings and events

- Individual customers

(13) Your group's flower shop needs to decide on its sourcing strategy. Which of the following solutions do you choose?

- Order from few exclusive flower wholesalers

- Order from many different flower wholesalers

(14) Your group's flower shop needs to decide on how to reward outstanding employees. Which of the following solutions do you choose?

- Personnel trainings

- Financial bonuses 
(15) Your group's flower shop needs to decide on a way to improve the stores. Which of the following solutions do you choose?

- Improve store design

- Improve store size

(16) Your group's flower shop needs to increase customer retention. Which of the following solutions do you choose?

- Loyalty card/bonus points

- Volume discounts

(17) Your group's flower shop needs to determine its key financial goal. Which of the following solutions do you choose?

- Increase sales growth

- Increase profit margins

(18) Your group's flower shop needs to decide on how to obtain market intelligence. Which of the following solutions do you choose?

- Set up an inhouse market research unit

- Hire a market research consultancy

(19) Your group's flower shop needs to decide which advertising channel to prioritize. Which of the following solutions do you choose?

- Advertising via Internet

- Advertising via local media

(20) Your group's flower shop needs to redesign its logo. Which of the following solutions do you choose?

- Make the logo blue

- Make the logo red

(21) Your group's flower shop needs to decide on whether or not to offer home delivery. Which of the following solutions do you choose?

- Offer delivery service - that's where the money is

- Don't offer delivery service-it's not worth the hefty investment

(22) Your group's flower shop needs to decide on its return policy. Which of the following solutions do you choose?

- "7 days fresh or your money back"

- "If you don't love it, we'll take it back"

(23) Your group's flower shop needs to decide on its expansion strategy. Which of the following solutions do you choose?

- Organic growth (growth from existing business)

- External growth (growth from acquiring other flower shops)

(24) Your group's flower shop needs to decide on its opening hours. Which of the following solutions do you choose?

- 9 a.m.-9 p.m. for all branches

- Store hours consistent with other stores in the local neighborhood
(25) Your group's flower shop needs to increase its reach among commercial customers. Which of the following solutions do you choose?

- Offer discounted flower subscriptions

- Hire a sales rep to go out to restaurants, funeral homes, etc.

\section{APPENDIX B}

\section{Study 1, Association Test-List of Items Used}

(1) Which of the four words listed below do you associate most with the keyword cow?

- horse

- farmer

- grass

- milk

(2) Which of the four words listed below do you associate most with the keyword water?

- rain

- fire

- drink

- well

(3) Which of the four words listed below do you associate most with the keyword house?

- apartment

- home

- roof

- school

(4) Which of the four words listed below do you associate most with the keyword film?

- director

- cinema

- camera

- movie

(5) Which of the four words listed below do you associate most with the keyword lamp?

- shade

- genie

- street

- desk

(6) Which of the four words listed below do you associate most with the keyword cup?

- tea

- coffee

- glass

- mug

(7) Which of the four words listed below do you associate most with the keyword phone?

- dial

- cell 
- ring

- call

(8) Which of the four words listed below do you associate most with the keyword book?

- page

- reservation

- story

- library

(9) Which of the four words listed below do you associate most with the keyword car?

- engine

- truck

- vehicle

- auto

(10) Which of the four words listed below do you associate most with the keyword pool?

- table

- water

- swim

- cue

(11) Which of the four numbers below do you associate most with the keynumber 12?

- 11

- 6

- 13

- 24
(12) Which of the four numbers below do you associate most with the keynumber 1111?

- 1110

- 1112

- 111

- 4

(13) Which of the four numbers below do you associate most with the keynumber $\mathbf{6 6}$ ?

- 99

- 12

- 6

- 3

(14) Which of the four numbers below do you associate most with the keynumber 101?

- 111

- 131

- 11

- 202

(15) Which of the four numbers below do you associate most with the keynumber $\mathbf{1}$ ?

- 0

- 2

- 11

- 10

\section{APPENDIX C}

\section{Study 1, Intergroup Reward Allocation Task-Tajfel Matrices Used}

(1) Please choose one of the following reward allocation structures:

Line 1: Rewards/penalties for Member 2 of your group ("inductive thinkers")

Line 2: Rewards/penalties for Member 3 of the other group ("deductive thinkers")

\begin{tabular}{rrrrrrrrrrrrrr}
\hline-19 & -16 & -13 & -10 & -7 & -4 & -1 & 0 & 1 & 2 & 3 & 4 & 5 \\
6 & 5 & 4 & 3 & 2 & 1 & 0 & -1 & -4 & -7 & -10 & -13 & -16 & -19 \\
\hline
\end{tabular}

(2) Please choose one of the following reward allocation structures:

Line 1: Rewards/penalties for Member 3 of your group ("inductive thinkers")

Line 2: Rewards/penalties for Member 1 of the other group ("deductive thinkers")

\begin{tabular}{rrrrrrrrrrrrr}
\hline 1 & 2 & 3 & 4 & 5 & 6 & 7 & 8 & 9 & 10 & 11 & 12 & 13 \\
14 & 13 & 12 & 11 & 10 & 9 & 8 & 7 & 6 & 5 & 4 & 3 & 2 \\
\hline
\end{tabular}


(3) Please choose one of the following reward allocation structures:

Line 1: Rewards/penalties for Member 4 of your group ("inductive thinkers")

Line 2: Rewards/penalties for Member 4 of the other group ("deductive thinkers")

\begin{tabular}{|c|c|c|c|c|c|c|c|c|c|c|c|c|c|}
\hline-14 & -12 & -10 & -8 & -6 & -4 & -2 & -1 & 3 & 7 & 11 & 15 & 19 & 23 \\
\hline 23 & 19 & 15 & 11 & 7 & 3 & -1 & -2 & -4 & -6 & -8 & -11 & -12 & -14 \\
\hline
\end{tabular}

(4) Please choose one of the following reward allocation structures:

Line 1: Rewards/penalties for Member 3 of your group ("inductive thinkers")

Line 2: Rewards/penalties for Member 2 of your group ("inductive thinkers")

\begin{tabular}{rrrrrrrrrrrrr}
\hline 12 & 10 & 8 & 6 & 4 & 2 & 0 & -1 & -5 & -9 & -13 & -17 & -21 \\
-25 & -21 & -17 & -13 & -9 & -5 & -1 & 0 & 2 & 4 & 6 & 8 & 10 \\
\hline
\end{tabular}

(5) Please choose one of the following reward allocation structures:

Line 1: Rewards/penalties for Member 4 of the other group ("deductive thinkers")

Line 2: Rewards/penalties for Member 3 of the other group ("deductive thinkers")

\begin{tabular}{rrrrrrrrrrrrr}
\hline 18 & 17 & 16 & 15 & 14 & 13 & 12 & 11 & 10 & 9 & 8 & 7 & 6 \\
5 & 6 & 7 & 8 & 9 & 10 & 11 & 12 & 13 & 14 & 15 & 16 & 17 \\
\hline
\end{tabular}

(6) Please choose one of the following reward allocation structures:

Line 1: Rewards/penalties for Member 2 of your group ("inductive thinkers")

Line 2: Rewards/penalties for Member 1 of the other group ("deductive thinkers")

\begin{tabular}{rrrrrrrrrrrrr}
\hline 17 & 14 & 11 & 8 & 5 & 2 & -1 & -2 & -3 & -4 & -5 & -6 & -7 \\
-8 & -7 & -6 & -5 & -4 & -3 & -2 & -1 & 2 & 5 & 8 & 11 & 14 \\
\hline
\end{tabular}

\section{APPENDIX D}

\section{Study 1, Group Involvement Questions ${ }^{\mathrm{a}}$}

Next, please indicate the extent to which you agree with the following statements:

(1) Relationships with other people are very important to me.

(2) I basically never feel lonely.

(3) Belonging to larger social entities and groups is a crucial part of life.

(4) Sometimes, the welfare of groups I belong to can be as important as my own personal welfare.

(5) I care about groups I belong to and want them to be different/better than other groups.

(anchored on a 9-point answer scale ranging from 1, "not at all," to 9, “very much").

\section{APPENDIX E}

\section{Study 1, Comprehension and Suspicion Checks}

Post-task questionnaire items were used to assess selfreported comprehension and suspicion regarding the task. The mean of the item "I understood the instructions well"with answer categories ranging from 1 , "strongly disagree," to 5 , "strongly agree"-was 4.21, suggesting that study comprehension was high. Further, the mean of the item "There were other participants involved in the task" was 4.33, indicating that participants were not suspicious about the ostensible group setting. In addition, an open-ended question asked participants to list any aspects of the experiment that they found "weird" or "hard to believe" (if any). While some of the participants expressed doubt that the association test was a valid instrument for discriminating between inductive and deductive thinkers, or that the specific group involvement score they were provided exactly matched their group involvement, the actual existence of other study participants and the reality of their responses were very rarely questioned.

\footnotetext{
a Based on Ellemers, Spears, and Doosje (1997).
} 
APPENDIX $F$

Correlation Tables

TABLE F1

Study 1

\begin{tabular}{|c|c|c|c|c|c|}
\hline & Variable & 1 & 2 & 3 & 4 \\
\hline 1 & Identification & 1 & & & \\
\hline 2 & Certainty & $0.36 * * *$ & 1 & & \\
\hline 3 & Attention & $-0.20 * *$ & -0.10 & 1 & \\
\hline 4 & Resistance & $0.24^{* * *}$ & $0.25^{* * *}$ & $-0.54^{* * *}$ & 1 \\
\hline
\end{tabular}

TABLE F2

Study 2

\begin{tabular}{llccc}
\hline \multicolumn{1}{c}{ Variable } & $\mathbf{1}$ & $\mathbf{2}$ & $\mathbf{3}$ \\
\hline 1 & Identity type & 1 & & \\
2 & Certainty & -0.01 & 1 & 1 \\
3 & Attention & $-0.18^{*}$ & 0.05 & $-0.18^{*}$ \\
4 & Resistance & $0.16^{*}$ & $0.19^{*}$ & 1 \\
\hline
\end{tabular}

Note: $n=173$.

${ }^{*} p \leq .05$

TABLE F3

Study 3

\begin{tabular}{|c|c|c|c|c|c|c|}
\hline & Variable & 1 & 2 & 3 & 4 & $\mathbf{5}$ \\
\hline 1 & Utilitarian identity & 1 & & & & \\
\hline 2 & Normative identity & $-0.50 * * *$ & 1 & & & \\
\hline 4 & Attention & $0.10^{*}$ & -0.07 & -0.03 & 1 & \\
\hline 5 & Resistance & $-0.13^{* *}$ & $0.20 * * *$ & -0.04 & $-0.23 * * *$ & 1 \\
\hline
\end{tabular}

Notes: $n=506$. Baseline: no identity/control condition.

${ }^{*} p \leq .05$

${ }^{* *} p \leq .01$

$* * * p \leq .001$ 


\section{APPENDIX G \\ FIGURE G1 \\ Study 1: Average Resistance to Environmental Pressures (Participants Staying with Their Initial Response) across Individual Trials}

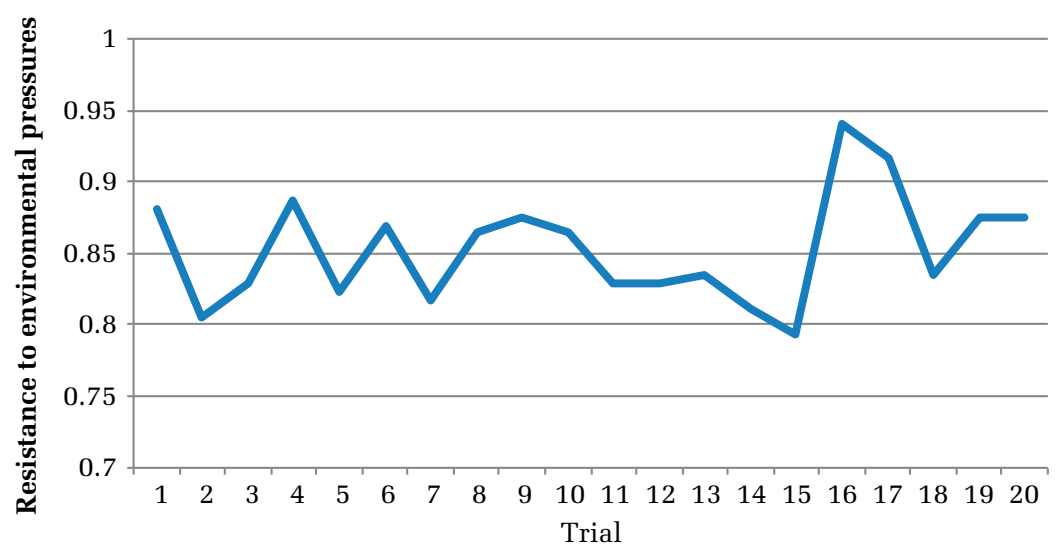

\section{Study 1, Post Hoc Analyses}

In supplementary post hoc analyses, I first explored potential gender effects by estimating a one-way ANOVA comparing resistance by gender. Results showed that gender had no significant effect, $F(1,167)=1.47, d=0.21, p>.10$.

Second, I explored temporal tendencies to determine whether respondents would learn to resist or accept environmental pressures throughout the trials of the experiment. Running a regression with resistance as dependent variable and trial number (ranging from 1 to 20 ) as independent variable yielded a nonsignificant coefficient $(b=0.01 ; S E=0.01$; $z=1.38 ; p>.10$ ). Manual inspection of the responses aggregated across participants at the trial level also failed to reveal any discernable cross-trial trends (see Figure G1).

Third, I assessed differences between the 20 focal trials in which the competitor's response ostensibly differed and the five trials in which there was agreement between the participant's and the competitor's initial choice. Running a paired samples $t$ test, I found that participants stayed with their previous choice significantly more frequently in the latter five trials $\left(M_{\text {control trials }}=0.94\right)$ than in the 20 focal trials $\left(M_{\text {focal }}\right.$ trials $=0.85), t=5.15, d f=168, d=0.60, p \leq .001$, indicating that response changes were indeed a consequence of environmental pressures and lending further credibility to the operationalization of the dependent variable.

\section{APPENDIX H}

\section{Study 2, Manipulation Checks}

After participants completed the main task, post-task questionnaire items were used to check the effectiveness of the manipulation. Specifically, I included four items in the post-task questionnaire, based on the measure devised by Gioia and Thomas (1996), that asked participants to characterize their group. The four questionnaire items were "Our group really cares about high quality," "Traditions and symbols are fundamental to our group's functioning," "Economic performance is considered key to fulfilling our mission," and "Financial returns are the central success measure for us." The response scale ranged from 1 ("strongly disagree") to 7 ("strongly agree"). Consistent with Gioia and Thomas (1996), I reverse-coded the last two items of the scale so that higher scores indicated a more normative identity.

The mean of the identity type measure $(\alpha=0.79)$ differed considerably between conditions; specifically, it was significantly higher in the normative identity condition $\left(M_{\text {normative }}\right.$ identity $=4.84)$ than in the utilitarian identity condition $\left(M_{\text {utilitarian identity }}=3.05\right), F(1,171)=115.06, d=1.64$, $p \leq .001$, supporting the effectiveness of the manipulation. As a supplementary manipulation check, I included an item asking participants where they saw their group on a 9point continuum, with "Investment Bank on Wall Street" and "Catholic Church" as anchors at the low and high ends of the scale, respectively. The mean of this item differed significantly between conditions, $F(1,171)=46.49, d=$ $1.03, p \leq .001$, with participants in the utilitarian identity condition providing responses closer to the investment bank end of the continuum $\left(M_{\text {utilitarian identity }}=2.91\right)$ and participants in the normative identity condition being closer to the church archetype $\left(M_{\text {normative identity }}=4.85\right)$. I also analyzed whether the identity type manipulation inadvertently led to differences in identification and found no significant difference in the perceived identification measure employed earlier $(\alpha=0.82)$ between conditions, $F(1,171)=1.33, d=0.17, p>.10$. Further, there was no significant difference between conditions in terms of the number of points allocated to in-group members in the reward allocation task, $F(1,171)=0.58, d=0.12, p>.10$. These results suggested that the manipulation was effective in inducing the two different types of identity 
(utilitarian and normative) while holding identification approximately constant.

\section{APPENDIX I}

\section{Study 2, Post Hoc Analyses}

Interestingly, I found a significant negative main effect of gender in the data of Study $2(b=-0.04 ; S E=0.02 ; t=$ 2.17; $p \leq .05$ ), suggesting that women showed less resistance to environmental pressures than men did. The interaction effect between identity type and gender, however, was not significant $(b=0.06 ; S E=0.04 ; t=1.45 ; p>.10)$. I reran all regressions for Study 2 with gender as a control, and the results remained qualitatively unchanged.

\section{APPENDIX J}

\section{Study 3, Main Task-Text}

How to engage in risk management is a complex strategic issue that the top management of virtually any company is facing these days. Your group's flower shop has consistently invested in risk management initiatives about as much as other companies in the industry and has never faced any serious problems related to risk management issues.

Not too long ago, the ISO developed a voluntary risk management standard for companies worldwide to consider-the ISO 31000, which provides principles, framework, and a process for managing risk. Topics that are covered by this particular standard range from implementation guidelines to risk assessment techniques.

ISO 31000 has been praised by some for helping companies to perform well in an environment full of uncertainty, but, at the same time, the standard is not without criticism. Opponents claim it permits only an overly narrow range of methods, has a narrow scope, cannot be universally integrated, and is full of illogical definitions of key terms.

To learn a bit more about ISO 31000, please click here: http://www.iso.org/iso/home/standards/iso31000.htm

Now you are asked to decide whether or not your flower shop should adopt ISO 31000 . To be clear, this is not a decision on whether to make greater investments in risk management generally; it is specifically a decision on whether to adopt this particular ISO 31000 standard.

\section{APPENDIX K}

\section{Study 3, Manipulation Checks}

An ANOVA revealed significant differences in the selfreported identity-type measure (see Study 2) across the three conditions, $F(2,503)=175.81, \eta^{2}=0.41, p \leq .001$. In support of the effectiveness of the manipulation, the mean was significantly higher in the normative identity condition $\left(M_{\text {normative identity }}=4.76\right)$ than in the utilitarian identity condition $\left(M_{\text {utilitarian identity }}=2.72\right), F(1,334)=$ 266.69, $d=1.78, p \leq .001$, and the control condition $\left(M_{\text {control }}=3.71\right), F(1,332)=112.33, d=1.15, p \leq .001$. These latter two conditions were also significantly different from each other, $F(1,340)=98.22, d=1.07, p \leq .001$. Similarly, participants in the three conditions differed significantly in their assessment on the "Investment Bank on Wall Street" versus "Catholic Church" scale previously used in Study 2, $F(2,503)=87.64, \eta^{2}=0.26, p \leq .001$, with the mean in the normative identity condition $\left(M_{\text {normative identity }}=\right.$ 5.13) being significantly higher than those in both the utilitarian identity condition $\left(M_{\text {utilitarian identity }}=2.55\right), F(1,334)=$ $169.12, d=1.42, p \leq .001$, and the control condition $\left(M_{\text {control }}\right.$ $=3.65), F(1,332)=55.20, d=0.49, p \leq .001$. The difference between the utilitarian identity and the control conditions on this measure was also statistically significant, $F(1,340)$ $=34.47, d=0.63, p \leq .001$.

Moreover, a comparison of the three conditions across levels of self-reported identification (see the measure from Study 1) was significant, $F(2,503)=31.36, \eta^{2}=0.11, p \leq .001$. There was a significantly lower identification in the control condition $\left(M_{\text {control }}=5.15\right)$ than in both the utilitarian identity $\left(M_{\text {utilitarian identity }}=6.47, F(1,340)=52.94, d=0.79, p \leq .001\right)$ and the normative identity conditions $\left(M_{\text {normative identity }}=\right.$ 6.20), $F(1,332)=37.73, d=0.67, p \leq .001$. These latter two conditions did not differ significantly from one another in terms of self-reported identification, $F(1,334)=2.42, d=0.16$, $p>.10$.

\section{APPENDIX L}

\section{Study 3, Post Hoc Analyses}

Similar to Study 2, results showed a negative main effect of gender on resistance that was significant at a $10 \%$ level $(b=$ $-0.39 ; S E=0.22 ; t=1.80 ; p=.07$ ), but the interaction terms of gender with the two condition dummies were not significant (ps > .10). Taken together, the gender-related post hoc analyses reported here, although inconclusive, indicate that there may be gender differences in people's susceptibility to environmental pressures-an intriguing exploratory finding worthy of further study.

Additionally, I was interested in exploring whether the results of Study 3 hold when restricting the sample to only those participants who had firsthand experience with organizational decision-making. I thus ran subgroup analyses among those who indicated they had such experience $(n=285)$. Consistent with the main results reported in the main body, one-way ANOVAs revealed greater resistance in the normative identity condition $\left(M_{\text {normative identity }}=\right.$ $5.71)$ than in the utilitarian identity condition $\left(M_{\text {utilitarian }}\right.$ identity $=4.38), F(1,181)=13.10, d=0.54, p \leq .001$, and in the control condition $\left(M_{\text {control }}=5.05\right), F(1,189)=3.52, d=$ $0.27, p=.06$. Moreover, the indirect effect of normative identity (vs. utilitarian identity) on resistance was significantly mediated by attention (95\% CI [0.001, 0.386]) but not certainty (95\% CI $[-0.124,0.026])$. 
Copyright of Academy of Management Journal is the property of Academy of Management and its content may not be copied or emailed to multiple sites or posted to a listserv without the copyright holder's express written permission. However, users may print, download, or email articles for individual use. 